\title{
$\begin{array}{ll}\text { Research Square } & \text { Preprints are preliminary reports that have not undergone peer review. } \\ \text { They should not be considered conclusive, used to inform clinical practice, }\end{array}$ or referenced by the media as validated information. \\ Suspension Parameters Matching Design for Robust Hunting Stability of High-speed Train
}

\section{Guang Li}

Southwest Jiaotong University https://orcid.org/0000-0002-3190-0357

Yuan Yao ( $\nabla$ yyuan8848@163.com )

State Key Laboratory of Traction Power, Southwest Jiaotong University, Chengdu 610031, China

\section{Yadong Song}

Southwest Jiaotong University

\section{Guosheng Chen}

CRRC Zhuzhou Locomotive CO.,LTD

\section{Kang Chen}

Southwest Jiaotong University

\section{Original Article}

Keywords: high-speed train, robust hunting stability, parameters design, parameters matching, design of experiment

Posted Date: February 4th, 2021

DOl: https://doi.org/10.21203/rs.3.rs-166491/v1

License: (c) (i) This work is licensed under a Creative Commons Attribution 4.0 International License. Read Full License 


\title{
Suspension Parameters Matching Design for Robust Hunting Stability of High-speed Train
}

\author{
Guang $\mathrm{Li}^{1}$, Yuan $\mathrm{Yao}^{1 *}$, Yadong Song ${ }^{1}$, Guosheng Chen ${ }^{2}$, Kang Chen ${ }^{1}$ \\ (1. State Key Laboratory of Traction Power, Southwest Jiaotong University, Chengdu 610031, China; \\ 2. State Key Laboratory of Heavy Duty AC Drive Electric Locomotive Systems Integration, Changsha \\ 412001, China)
}

\begin{abstract}
Hunting stability of high-speed train is an important dynamic performance for the design of bogie suspension parameters. An appropriate hunting stability margin is required for high-speed train. Besides, a remarkable ability to weaken the influence caused by the disturbance of bogie suspension parameters and wheel-rail contact parameters on hunting stability is also required. The matching design of bogie passive suspension parameters is an important means to ensure the train comprehensive stability. In this paper, the concept of robust hunting stability is proposed, and the indexes for suspension parameter robustness and wheel-rail contact equivalent conicity robustness are defined and chosen as the dynamic performance indexes for the bogie suspension parameters design. Design of Experiment (DOE) is used to search the suspension parameters to satisfy the defined robust hunting stability indexes. Vehicle linear stability analysis is performed based on a large number of combined random suspension parameters, and then the parameters satisfying the performance requirements are designed, from which the parameter matching rules are concluded based on the discrete statistical analysis. Using this method, the suspension parameters can be designed to satisfy the defined multiple vehicle dynamic performance indexes, instead of engineering experiences.
\end{abstract}

Keywords: high-speed train, robust hunting stability, parameters design, parameters matching, design of experiment.

\section{Introduction}

Hunting stability is the centrality of railway vehicle design and dynamics researches. Although the lateral stability of the railway vehicles can be strengthened with the help of advanced mechanisms and active suspension systems, the optimization of the conventional passive suspension elements still could be considered as one of the efficient methods ${ }^{[1-8]}$. In the suspension parameter design of railway

* Corresponding author.E-mail:yyuan8848@163.com

This project is supported by National Natural Science Foundation of China(Grant No. 51675443, 51735012), Development and Verification Technology of Key Components of Adaptive Bogie(Grant No. 2018YFB1201703), The Independent Projects of Traction Power State Key Laboratory(Grant No.2019TPL Q07), and Research and Development project of China Railway Group (Grant No.N2020J026) vehicles, the main task is to find a compromise suspension parameter design, which takes into account the performance indexes such as lateral stability, ride comfort and curve passing capacity simultaneously. Many scholars adopt the genetic algorithm(GA) to optimize the suspension parameters of railway vehicles ${ }^{[9-13]}$, whose research contents involve the lateral stability and curve passing performance, wear and ride comfort of railway vehicles, and the optimal performance and the suspension parameters match of the vehicle system are obtained. However, the function of GA method is to search the optimal solution by simulating the process of natural evolution, so the matching relationship of some secondary parameters is sometimes neglected. The Design of Experiment (DOE) can make up for the shortcoming of the GA method. The sufficient and comprehensive data can be obtained by selecting appropriate DOE method, 
which is very helpful to judge the influence degree of each suspension parameter and get accurate and reliable conclusions ${ }^{[14]}$. The application of DOE method in aviation, machinery and other fields is more mature, but the application in railway vehicles is still relatively few.

Several studies on improving hunting stability of railway vehicles have been carried out ${ }^{[15-20]}$. The influences of suspension parameters on vehicle stability and curve passing performance are also taken into account in the optimization of bogie suspension parameters. The vehicle curve passing performance is often affected by the stiffness of secondary horizontal suspension, while the vehicle stability can be affected by more suspension parameters. In this paper, suspension parameters affecting the vehicle lateral dynamic performance are decoupled, and the optimization for the bogie horizontal suspension stiffness is conducted, except for the secondary horizontal stiffness. Reasonable matching for the bogie suspension parameters is conducive to improving the hunting stability margin and enhancing the ability to resist the influence caused by the disturbance of bogie suspension parameters and wheel-rail contact parameters on the vehicle hunting stability. That is to say, the vehicles have a strong adaptability for variation of suspension parameters and some track parameters. The matching design of bogie passive suspension parameters is an important means to ensure the train comprehensive stability. In this study, the suspension parameters matching rules are investigated to enhance the robust hunting stability of high-speed train.

The optimization and matching of bogie suspension parameters is particularly important for the design of vehicle robust hunting stability. Therefore, the design for hunting stability of bogie suspension parameters is also a process of multi-objective optimization, and the hunting stability margin of vehicles, as well as the robustness of bogie suspension parameters and the track adaptability should be taken into account. In this regard, the bogie suspension parameters matching for robust hunting stability is considered. A method for the optimization of key bogie suspension parameters based on vehicle robust hunting stability is presented in this study. The design objectives for the vehicle hunting stability are defined, and chosen as the dynamic performance indexes for the bogie suspension parameters matching. The DOE method is utilized to search the suspension parameters to satisfy the defined robust hunting stability indexes. Vehicle linear stability analysis is performed based on a large number of combined random suspension parameters, and then the parameters satisfying the performance requirements are selected, from which the parameters matching rules are concluded based on the discrete statistical analysis. Using this method, the suspension parameters can be designed to satisfy the defined multiple vehicle dynamic performance indexes, instead of engineering experiences.

The present paper is an extension of our previous paper ${ }^{[21]}$. Compared with the previous study, there are three main differences in this article. (1) The optimization methods of suspension parameters are different. The NSGAII genetic algorithm was utilized in the previous paper, yet this paper adopt the method of parameters design. The advantage of the genetic algorithm is to obtain the optimal result quickly, but the matching rule between some secondary parameters is sometimes ignored. The DOE optimization method can remedy this weakness, which can help to discover more comprehensive parameter matching rules. (2) The analysis methods for optimization result data are different. Discrete statistical analysis is used in this paper, however, the previous paper adopt the partial correlation coefficient. (3) The scope of parameter matching is expanded. The matching relationship between equivalent conicity and key suspension parameters is also included in the research content.

\section{The robust stability design}

\subsection{The vehicle linear dynamics model}

Aim at studying the vehicle hunting stability, a simplified vehicle lateral dynamic model with 25 degrees of freedom is built, as shown in Fig. 1. There are seven rigid bodies, including four wheelsets, two frames, and one carbody. The wheelsets have lateral and yaw degrees of freedom(DOFS), while the carbody and the frame have lateral, yaw and roll degrees of freedom. The primary suspension is between the frame and the wheelset, which contains lateral, longitudinal and vertical positioning stiffness. Moreover, the primary rotating arm axle box 
structure is take into account in the model. The secondary suspension is between the frame and the carbody, which contains lateral, longitudinal and vertical stiffness, damping and anti-roll stiffness. Besides, the yaw damper and the secondary lateral damper are also established based on the Maxwell model, which is to analyze the effects of series stiffness of the oil damper on vehicle stability ${ }^{[22]}$. In this paper, the wheel-rail contact geometry is expressed by equivalent conicity, because the linear stability of the established vehicle model is the focus of the analysis here, and the wheel-rail tangential force is calculated through the theory of linear Kalker. involving one type of high-speed EMU in China ${ }^{[23,24]}$, the specific parameters of the model are expressed in Appendix Table 1. The equation of the system dynamics model is as follows,

$$
M \ddot{x}(t)+C \dot{x}(t)+K x(t)=Q
$$

The $\mathrm{x}$ represents the degree of freedom vector of the vehicle system. The matrices $\mathrm{M}, \mathrm{C}, \mathrm{K}$, and $\mathrm{Q}$ are respectively the mass, damping, stiffness and external force components of the vehicle system. With regard to the motion equation of a single wheelset with an elastic primary suspension, the lateral and yaw movement of wheelset are coupled by the wheel-rail tangential forces $^{[25,26]}$. The $\mathrm{K}$ is an asymmetric stiffness matrix, and the non-diagonal items reflect the coupling of the wheelset's lateral and yaw movement caused by the interaction of wheel and rail in tangential. The system damping $\mathrm{C}$ has a close relationship with the running speed $v$. In a period of hunting motion, the linear vehicle system is in the critical stability state only if the input energy and the consumed energy of the vehicle system are equal. Furthermore, the vehicle linear critical speed is the corresponding speed $v$.

As the result of the unsymmetrical nature of the stiffness matrix K, Eq. (1) cannot be converted into an uncoupled set of differential equations through customary methods of modal analysis, i.e., using only real modes. But a solution can still be gained by utilizing the complex modal transformation ${ }^{[2,27]}$. Eq. (1) is rewritten into the following state-space form,

$$
\dot{y}(\mathrm{t})=\operatorname{Ay}(\mathrm{t})
$$

The vector $\mathbf{y}$ is the system state variable vector, and the system matrix $\mathrm{A}$ is given by,

$$
A=\left[\begin{array}{cc}
0_{25 \times 25} & I_{25 \times 25} \\
-M^{-1} K & -M^{-1} C
\end{array}\right]
$$

The modal shapes and linear stability index of the vehicle system are obtained by analyzing the eigenvectors and eigenvalues of $\mathrm{A}$.

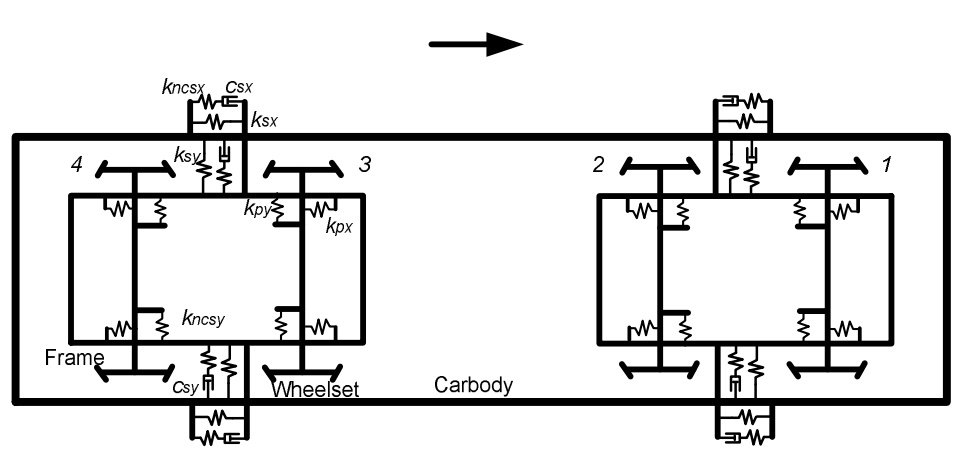

(a)

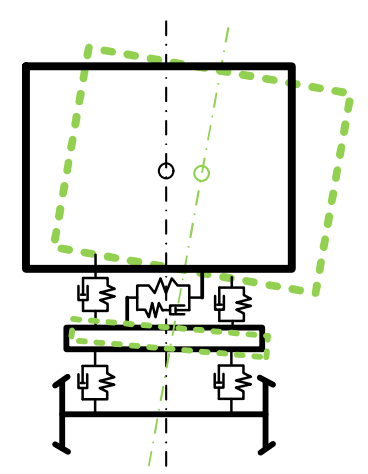

(b)

Fig. 1. Simplified vehicle lateral dynamic model

It is essential to consider the vehicle running performance on straight track and the curve passing performance when the bogie suspension parameters are designed ${ }^{[28]}$. In the light of the research experience, the vehicle ride stability and curve passing performance are greatly affected by the horizontal stiffness of the bogie secondary suspension, which has almost no impact on the vehicle hunting stability though. Besides, the variation range of the stiffness of the secondary air spring for the high-speed train is minor. The vehicle hunting stability is 
principal studied in this paper, so the lateral stiffness of the secondary suspension is not considered in the optimization. This paper mainly pay attention to the key bogie suspension parameters which impress the hunting stability of railway vehicles, for instance, the primary longitudinal stiffness $k p x$, the primary lateral stiffness $k p y$, the damping of yaw damper csx, the damping of secondary lateral damper csy, the yaw damper series stiffness kncsx and the secondary lateral damper series stiffness kncsy, which are selected as optimization objects to improve the robust hunting stability for railway vehicles.

\subsection{Robust stability index}

Horizontal suspension parameters of high-speed train bogies have a remarkable influence on the vehicle lateral dynamic performance, which mainly reflected in the lateral comfort, curve passing performance and hunting stability. Due to the high running speed, the vehicle hunting stability is the most important index, which must be got much attention in the design.

Errors that inevitably occur in the design and manufacture of bogie suspension components, and the creep or failure of rubber joints and hydraulic dampers, can result in the change of suspension stiffness and damping, and then affect the vehicle dynamics performances. In addition, the change of wheel-rail contact geometry caused by the rail deformation and the tread and rail head wear will also affect the vehicle dynamic performance. Therefore, a large hunting stability margin in a wide speed range is required for the high speed train, as well as remarkable ability to resist the influence caused by the disturbance of bogie suspension parameters and wheel-rail contact parameters on vehicle lateral stability is required. That is to say, the trains need a strong adaptability for suspension parameters and wheel-rail interactions.

The vehicle running stability at different equivalent conicity, suspension parameter robustness and wheel-rail equivalent conicity robustness defined as the robust hunting stability are taken into account in the designing and matching for bogie suspension parameters. The eigenvalues of the system matrix are calculated for the vehicle linear dynamic model. The ratio of real part of eigenvalues to the modulus corresponding to hunting mode regarded as the natural modal damping is defined as the linear stability index of the system, which is represented by $\zeta$. When $\zeta$ is negative, it shows that the linear model is stable. The $\zeta_{\text {low }}$ and $\zeta_{\text {norm }}$ are the low conicity and normal conicity stability indexes of vehicles corresponding to the equivalent conicity of 0.05 and 0.17 , and the corresponding running speed in this study are $200 \mathrm{~km} / \mathrm{h}$ and $350 \mathrm{~km} / \mathrm{h}$, respectively. The smaller the index value, the more stable the system. In order to evaluate the influence of disturbance resulting from bogie suspension parameters and wheel-rail contact parameters on the vehicle hunting stability, the suspension parameters are distributed in a certain range, and the stability indexes of the system are calculated with the different combined suspension parameters, and the standard deviation is defined as the suspension parameter robustness index. Similarly, the standard deviation of the stability index corresponding to the equivalent conicity distributed in a certain range of the system is defined as the equivalent conicity robustness index, denoted by $\operatorname{std}\left(\zeta_{\text {par }}\right)$ and $\operatorname{std}\left(\zeta_{\lambda}\right)$, respectively. The smaller the two index values, the smaller the influence of suspension parameters and equivalent conicity on the system stability, and the stronger the corresponding robustness. The suspension parameter robustness index is obtained by calculating the 1000 groups of suspension parameters with uniform distribution in the range of $( \pm 20 \%)$ and randomly combined, and the equivalent conicity robustness index is obtained by analyzing the different equivalent conicity uniformly distributed in the range of 0.05-0.3 in this study. The robust stability indexes and corresponding calculation conditions are shown in Table 1.

\subsection{Design process}

Taking the simplified vehicle lateral dynamic model as the research object, the low conicity stability index $\zeta_{\text {low }}$, normal conicity stability index $\zeta_{\text {norm}}$, suspension parameter robustness index $\operatorname{std}\left(\zeta_{\text {par }}\right)$ and equivalent conicity robustness index $\operatorname{std}(\zeta \lambda)$ are selected as design objectives, whose calculation conditions and threshold settings are shown in Table 1 . 
According to experience, the main suspension parameters affecting the lateral stability of vehicles mainly include the primary longitudinal stiffness $k p x$, the primary lateral stiffness $k p y$, the damping of yaw damper csx, the damping of secondary lateral damper csy, the yaw damper series stiffness kncsx and the secondary lateral damper series stiffness kncsy. Accordingly, the six key suspension parameters are optimized, and the range of the six key suspension parameters is shown in Table 2. The specific design process is shown in Fig. 2.

Table 1. Robust stability indexes and threshold

\begin{tabular}{ccccc}
\hline \multirow{2}{*}{ Index } & \multicolumn{2}{c}{ Calculation condition } & \multirow{2}{*}{ Threshold } & Description \\
\cline { 2 - 4 } & $v(\mathrm{~km} / \mathrm{h})$ & $\lambda$ & & Low conicity stability index \\
\hline$\zeta_{\text {low }}$ & 200 & 0.05 & {$[-0.40,0.05]$} & Normal conicity stability index \\
$\zeta_{\text {norm }}$ & 350 & 0.17 & {$[-0.25,-0.15]$} & Suspension parameter robustness index \\
$\operatorname{std}\left(\zeta_{\text {par }}\right)$ & 350 & 0.17 & $\leq 0.045$ & Sun \\
$\operatorname{std}\left(\zeta_{\lambda}\right)$ & 350 & 0.17 & $\leq 0.15$ & Equivalent conicity robustness index \\
\hline
\end{tabular}

Table 2. Calculation range and discrete intervals of suspension parameters

\begin{tabular}{ccccccc}
\hline $\boldsymbol{N}$ & $\begin{array}{c}k p x \\
(\mathrm{kN} / \mathrm{mm})\end{array}$ & $\begin{array}{c}k p y \\
(\mathrm{kN} / \mathrm{mm})\end{array}$ & $\begin{array}{c}c s x \\
(\mathrm{kN} \mathrm{s} / \mathrm{m})\end{array}$ & $\begin{array}{c}c s y \\
(\mathrm{kN} \mathrm{s} / \mathrm{m})\end{array}$ & $\begin{array}{c}k n c s x \\
(\mathrm{kN} / \mathrm{mm})\end{array}$ & $\begin{array}{c}k n c s y \\
(\mathrm{kN} / \mathrm{mm})\end{array}$ \\
\hline $\mathbf{1}$ & $10 \sim 28$ & $3 \sim 5.4$ & $300 \sim 1240$ & $10 \sim 18$ & $5 \sim 9$ & $5 \sim 9$ \\
$\mathbf{2}$ & $28 \sim 46$ & $5.4 \sim 7.8$ & $1240 \sim 2180$ & $18 \sim 26$ & $9 \sim 13$ & $9 \sim 13$ \\
$\mathbf{3}$ & $46 \sim 64$ & $7.8 \sim 10.2$ & $2180 \sim 3120$ & $26 \sim 34$ & $13 \sim 17$ & $13 \sim 17$ \\
$\mathbf{4}$ & $64 \sim 82$ & $10.2 \sim 12.6$ & $3120 \sim 4060$ & $34 \sim 42$ & $17 \sim 21$ & $17 \sim 21$ \\
$\mathbf{5}$ & $82 \sim 100$ & $12.6 \sim 15.0$ & $4060 \sim 5000$ & $42 \sim 50$ & $21 \sim 25$ & $21 \sim 25$ \\
\hline
\end{tabular}

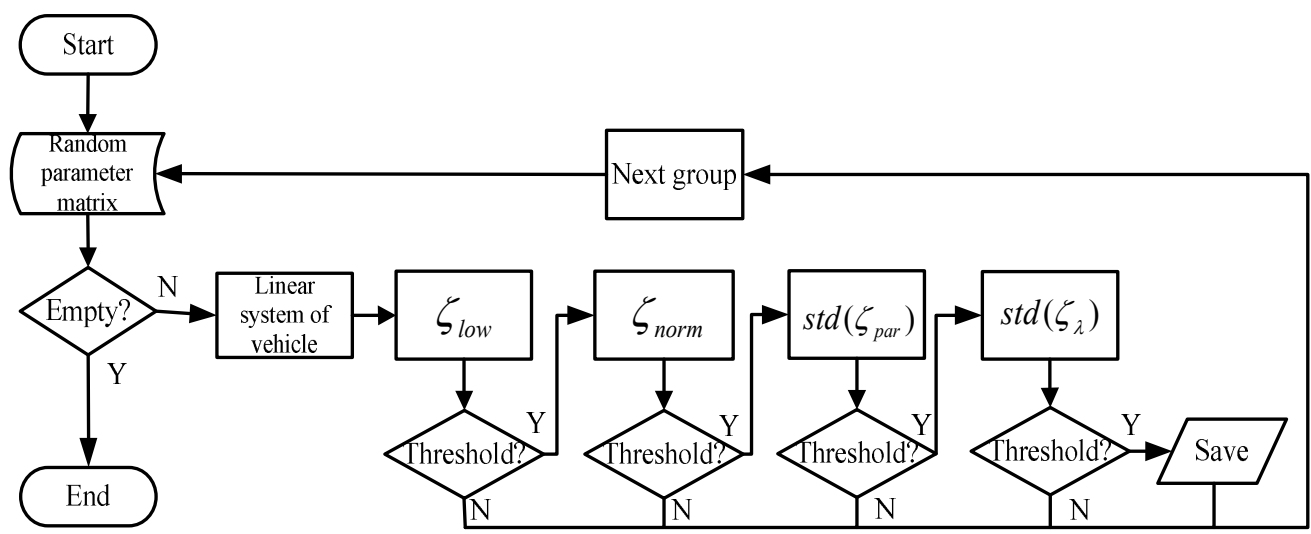

Fig. 2. Design process of the suspension parameters

A suspension parameter matrix is consisted of 50,000 groups of random parameter sets with uniform distribution were generated by MATLAB software for the six key suspension parameters. Subsequently, the generated random parameter sets are assigned to the vehicle linear dynamics model one by one, and the corresponding model is successively analyzed with the objective of $\zeta_{\text {low }}, \zeta_{\text {norm }}, \operatorname{std}\left(\zeta_{\text {par }}\right)$ and $\operatorname{std}\left(\zeta_{\lambda}\right)$. After each calculation, the calculation result will be judged.

When the calculation result exceeds the corresponding threshold range, the calculation corresponding to this random parameter set for the next objective will not be performed. If the corresponding random parameter set satisfies the requirements of all design objectives, the group of random parameter set will be saved, and the next group will be called to continue the process. Finally, all groups of the suspension parameter sets satisfying the four design objectives are obtained from a large number of random parameter sets.

\section{The matching laws of suspension parameters}




\subsection{Design results and discretization}

According to the design process in Section 2.3, the bogie suspension parameters combinations are obtained, of whose corresponding vehicles robust stability indexes meet the preset threshold range. As shown in Fig. 3(a), the six key suspension parameters (marked as $p 1 \sim p 6$ ) in each group are represented by a same color polyline, and the values of all groups are normalized to show the six key suspension parameters in a figure. The abscissa represents the six key suspension parameters and the ordinate represents the normalization values, where the number 1 represents the largest value and 0 represents the smallest value. It can be observed that the obvious matching rules between the six key suspension parameters. In other words, the value of one or several parameters will affect the matching values of other parameters. In order to mine the matching rules of the six suspension parameters, the discrete statistical method is used to count the occurrence times of the valid suspension parameter sets. According to Table 2, the calculation range of each suspension parameters is divided into five segments, which are represented by the number of $1,2,3,4$, and 5 , corresponding to parameter ranges of Min, Small, Medium, Large, and Max. Fig. 3(b) is a polyline graph with the discrete data of valid suspension parameters, whose every polyline corresponds to a valid matching rule of the six key suspension parameters. After counting the discrete polylines, the more occurrence times of a same polyline, the more obvious the matching rule is.

Fig. 4 and Fig. 5 show the occurrence times of the valid parameter matching for combinations in different ranges after different suspension parameters are discrete, which illustrate matching rules of the suspension parameters further. Besides, the horizontal axis of the three-dimensional histogram in the figures represents the discrete interval of two suspension parameters, and the vertical axis represents the number of statistics. Fig. 4 shows the matching rule of kpx, csx and kncsx. On one hand, when the discrete interval of kncsx is equal to 1, which indicates that the value of kncsx is selected within the parameter range of Min, the occurrence times of valid suspension parameters sets is the most, and the valid parameter set always appears regardless of the values of $k p x$ and $\operatorname{csx}$. On the other hand, when the discrete interval of kncsx is 3 , the occurrence times of a small kpx with a small is the most, or a small $k p x$ is required if $\operatorname{cs} x$ adopts a larger value, vice versa. It is also observed from Fig. 4 that the larger the value of kncsx, the fewer the statistics times. Namely, when the kncsx chooses a smaller value, its suspension parameter matching has a strong adaptability. Moreover, when the value of kncsx increases, it is necessary to reduce the value of suspension parameters along the longitudinal direction of the bogie, such as $k p x$ and $\operatorname{csx}$. Similarly, Fig. 5 shows the matching rule between kpx, kpy and csy, and the larger the value of $c s y$, the more statistics times. When $c s y$ adopts a value within the range of Small, $k p x$ and kpy show a negative correlation. In other words, the larger the value of $k p x$, the smaller the value of kpy is required to match.
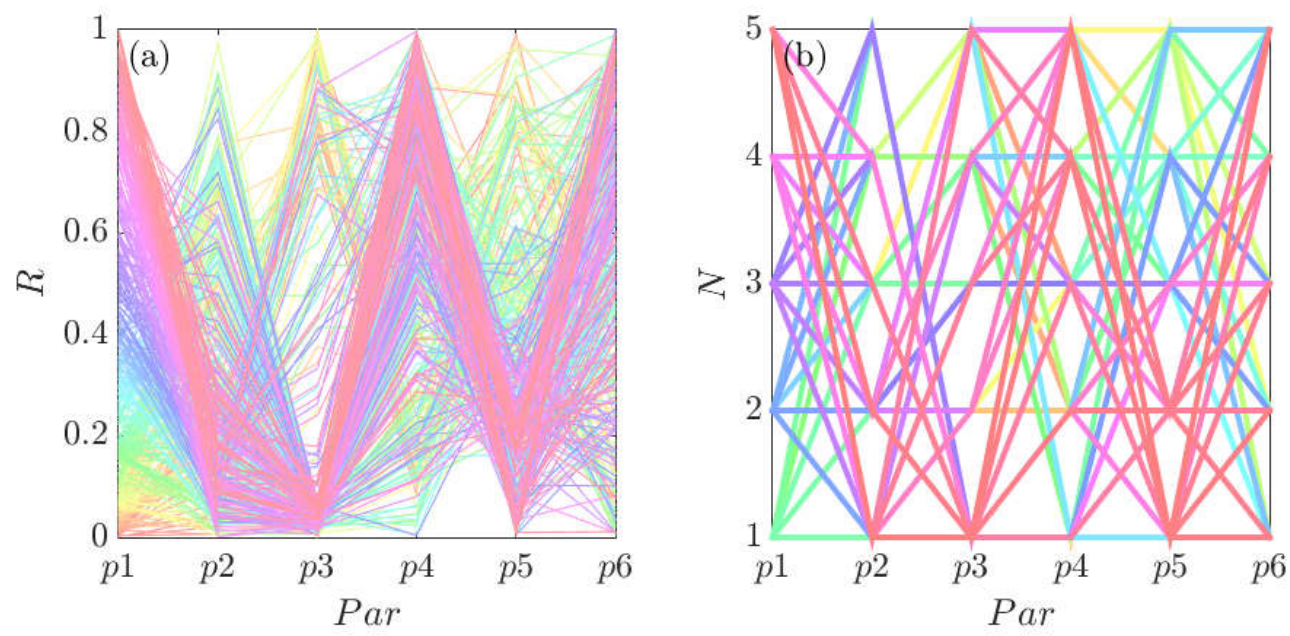

Fig. 3. Design of regularization parameters and discrete statistics 

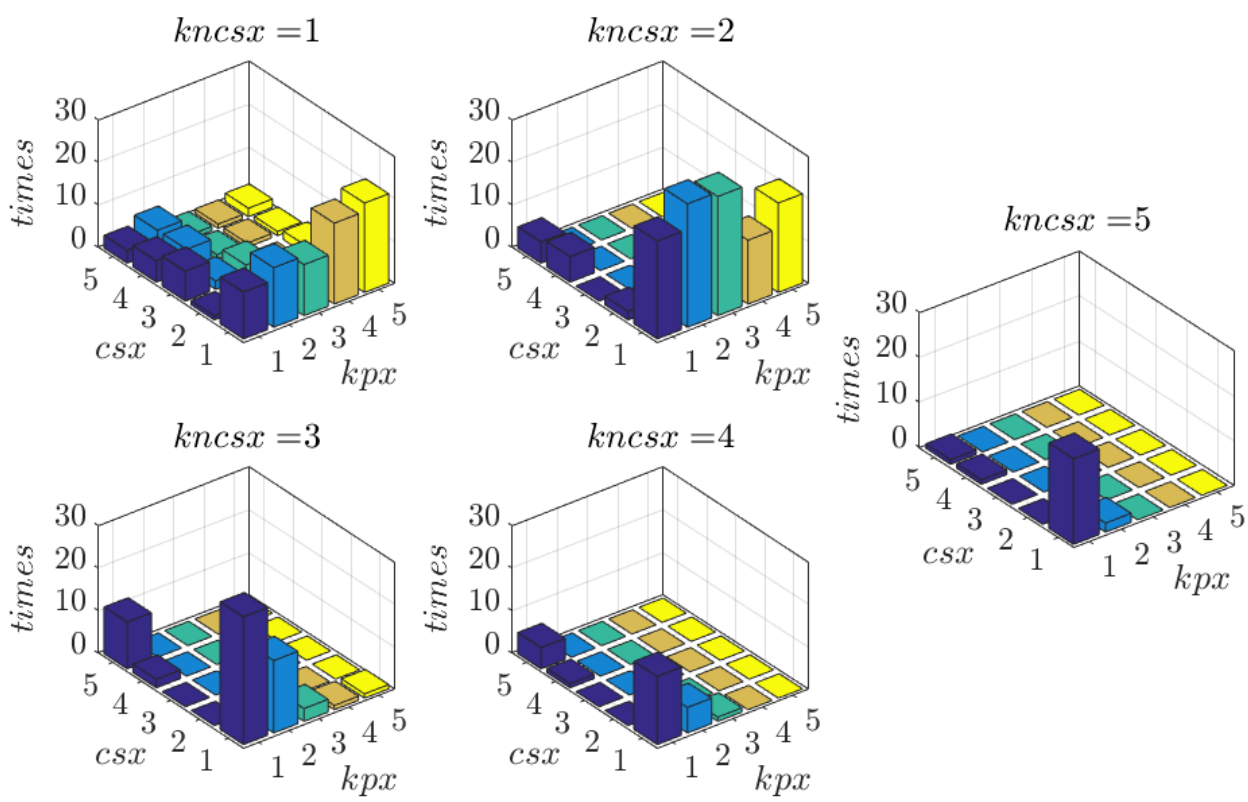

Fig. 4. Parameters matching results of kpx, csx and kncsx
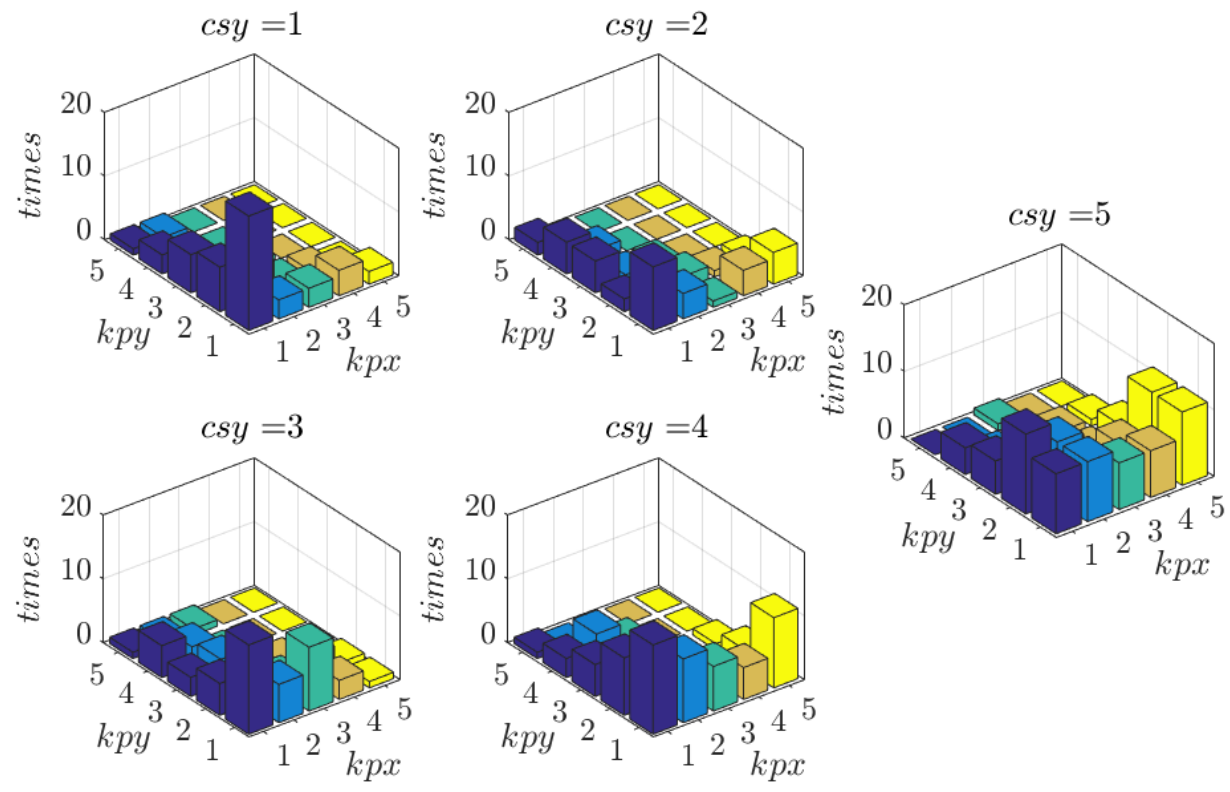

Fig. 5. Parameters matching results of kpx, kpy and csy

\subsection{Single-index analysis}

Fig. 3 shows the design results for the preset range of design objectives in Table 1. The preset range in this table is relatively wide because some values of design objectives are contradictory, such as $\zeta_{\text {low }}$ and $\operatorname{std}\left(\zeta_{\lambda}\right)$. If the preset range of low is extremely narrow, there is no valid parameter sets that meets the requirements of a narrow $\operatorname{std}\left(\zeta_{\lambda}\right)$. Therefore, the design of suspension parameters requires balancing multiple performance indexes. In order to analyze the suspension parameter matching rule corresponding to a specific index, we further reduce the preset range of the corresponding design objective based on the design results in Fig. 3, to limit the valid suspension parameter sets, which makes the parameter matching rule satisfying the specific index clearer. The calculation conditions for single-index analysis are the same as the calculation conditions in Table 1 , but the corresponding threshold settings are different. The values of $K$ equal to 1,2, and 3 respectively corresponding to the analysis condition of specific indexes of low conicity stability index $\zeta_{\text {low }}$, the suspension parameter robustness index $\operatorname{std}\left(\zeta_{\text {par }}\right)$ and the equivalent conicity robustness 
index $\operatorname{std}(\zeta \lambda)$. The following are called as the First Condition, the Second Condition and the Third Condition for brevity. The threshold settings for the three single-index analysis are $\left[-0.40 \leq \zeta_{\text {low }} \leq-0.25\right], \quad\left[\operatorname{std}\left(\zeta_{\text {par }}\right) \quad \leq 0.035\right] \quad$ and $\left[\operatorname{std}\left(\zeta_{\lambda}\right) \leq 0.055\right]$, respectively.

Fig. 6 is the tail box diagram showing the distribution of index values corresponding to the single-objective analysis condition, in which the abscissa is the analysis condition and the ordinate is the performance index value. It is observed that, for the design results of the First Condition, the corresponding values of $\zeta_{\text {low }}$ and $\zeta_{\text {norm }}$ are the smallest, which indicates that the design results of the First Condition are obviously superior to the other two single-objective analysis conditions in terms of low conicity stability and normal conicity stability. But it's values of $\operatorname{std}\left(\zeta_{p a r}\right)$ and $\operatorname{std}\left(\zeta_{\lambda}\right)$ are relatively larger than the other two conditions, especially the latter, which signifies that the equivalent conicity robust is extremely poor. Conversely, regarding the Third Condition, the value of $\operatorname{std}\left(\zeta_{\lambda}\right)$ is the smallest, which represents the equivalent conicity robustness is the best among them. Comparing the Second Condition and the Third Condition, the values of $\zeta_{\text {low }}$ and $\operatorname{std}\left(\zeta_{\lambda}\right)$ are similar, but the former has a better normal conicity stability than the latter. The distribution and matching rules of suspension parameters under these three conditions are discussed seriously in Sections 3.3 3.5.
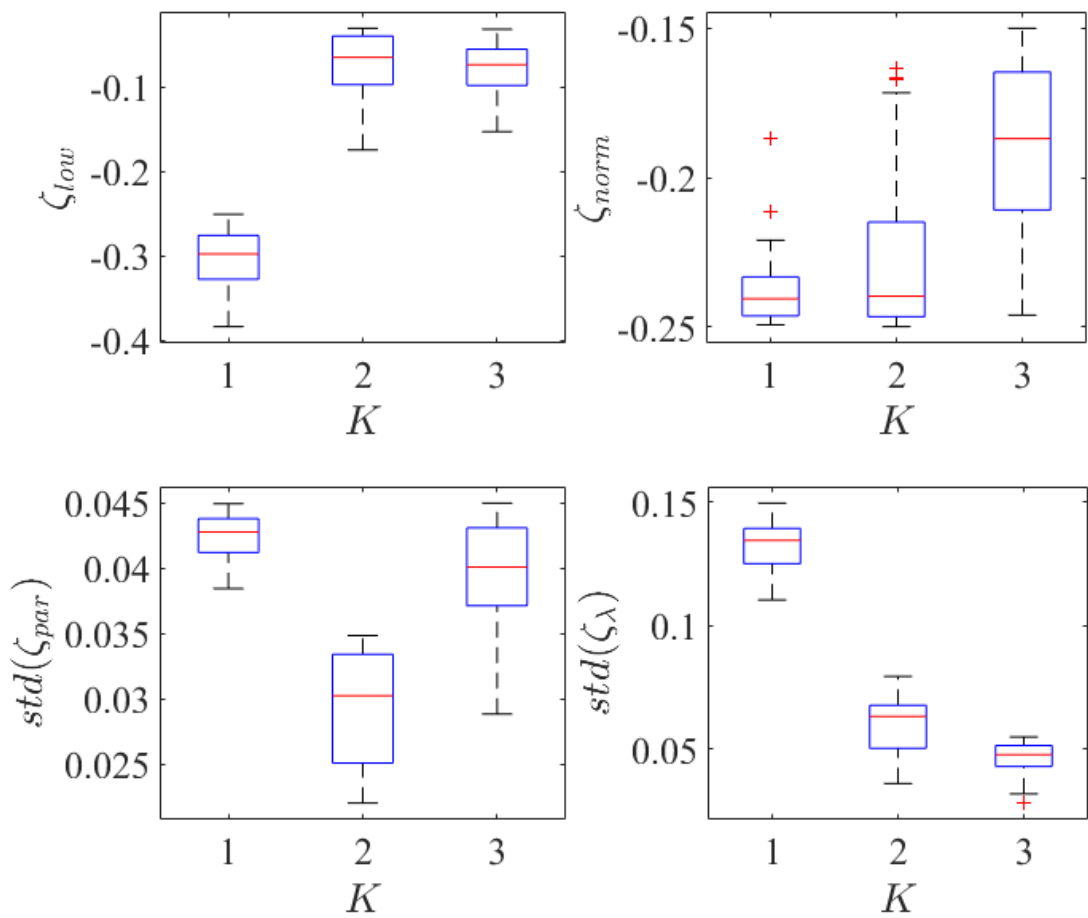

Fig. 6. Distribution of index values of single-objective analysis

\subsection{Low conicity stability}

The low concity instability occurs on high-speed trains occasionally, especially when the status of the wheel tread and rail head is new. When the low concity instability of vehicles occurs, the carbody is prone to hunting instability in low-frequency, and the ride comfort is deteriorated. So the low conicity stability is a very important performance index when the suspension parameters are optimized and matched. Fig. 7 shows the suspension parameters design results for the First Condition in the single-objective analysis. As shown in the figure, Fig. 7(a) is composed of 39 polylines, which means that there are 39 groups of random parameter sets satisfying the threshold of low conicity stability index $\zeta_{\text {low }}$, and Fig. 7(b) is the distribution of valid suspension parameters for the First Condition. It is observed that, no matter what other suspension parameters take, the suspension parameters matching of the vehicle system requires a larger $p 4(c s y)$ and a smaller $p 5$ (kncsx) to match. In other words, it is necessary to increase the value of $c s y$ and reduce 
the value of kncsx so as to improve the low conicity hunting stability of vehicles. In addition, $k p x$ and kpy exhibit a negative correlation, which is consistent with the analysis result of Fig. 5.

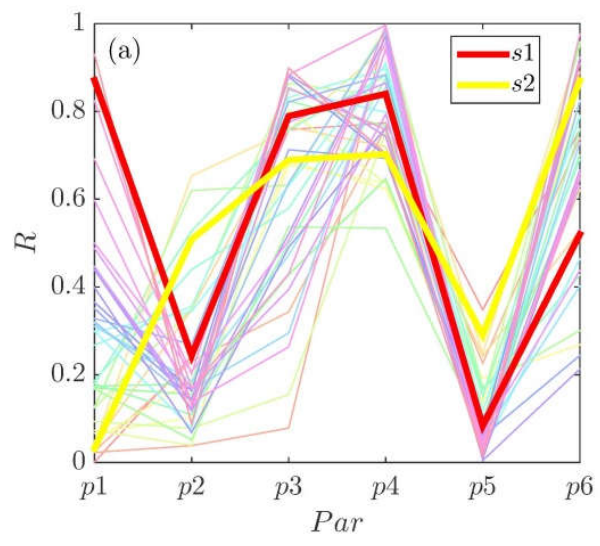

Besides, the polylines $s 1$ and $s 2$ in Fig. 7(a) are selected as two groups of typical suspension parameter sets for the subsequent dynamic performance analysis.

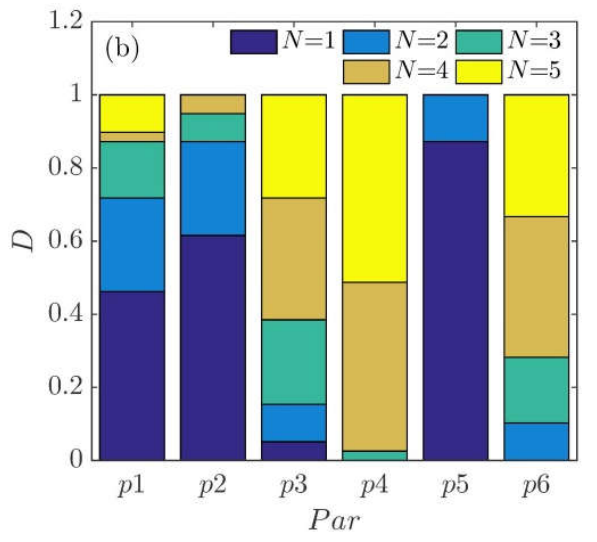

Fig. 7. Parameters matching and distribution for low conicity stability

\subsection{Suspension parameter robustness}

The suspension parameter robustness is an important performance index for the bogie suspension parameters matching as well, and the strong suspension parameter robustness indicates that the sensitivity of the vehicle system to suspension parameters is weakened. That is to say, the change of suspension parameters caused by the manufacturing error and failure as well as the creep deformation of suspension elements has little effect on the vehicle hunting stability. Fig. 8 shows the suspension parameters design results for the Second Condition in single-objective analysis. As illustrated in the figure, there are 49 polylines in Fig. 8(a), which means that there are 49 groups of parameter sets satisfying the threshold of suspension parameter robustness index $\operatorname{std}\left(\zeta_{\text {par }}\right)$. Fig. $8(\mathrm{~b})$ is the distribution of valid suspension parameters for the Second Condition. Moreover, it can be

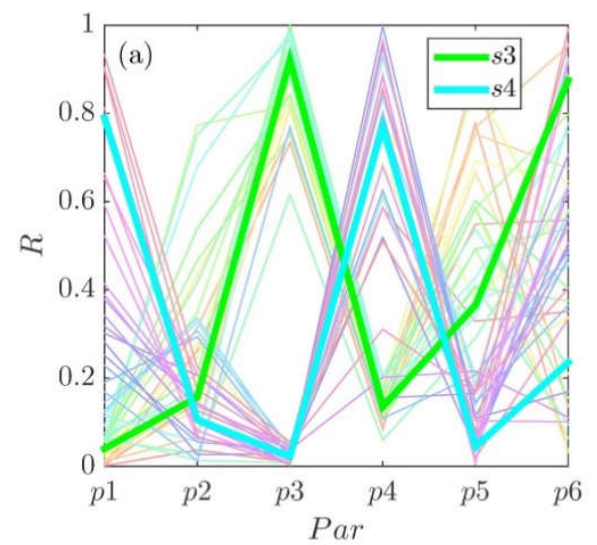

drawn that there are two types of obvious parameters matching rules from the figure. The suspension parameters matching is combined with larger value of csx, and smaller values of $c s y$ and $k p x$, which is a type of matching rule. The other type of parameters matching rule is composed of larger value of csy and smaller values of csx and kncsx, which is contrary to the former. And the two types of typical suspension parameters matching rules can both ensure the suspension parameter robustness. Furthermore, the distribution of kncsy is relatively symmetrical in the Fig., which indicates that the effect of kncsy on the suspension parameter robustness is not very obvious. Besides, the polylines $s 3$ and $s 4$ in Fig. 8(a) are selected as two groups of typical suspension parameter sets for the subsequent dynamic performance analysis.

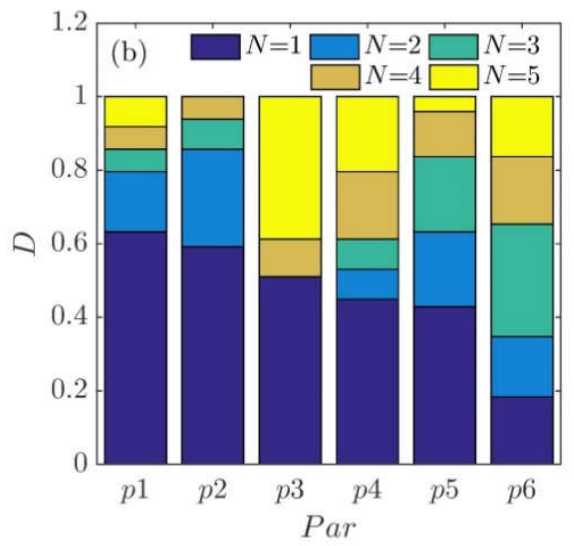

Fig. 8. Parameters matching and distribution for suspension parameter robustness 


\subsection{Equivalent conicity robustness}

The equivalent conicity robustness is also an important performance index for the bogie suspension parameters matching design. The strong equivalent conicity robustness indicates that the stability of vehicles is insensitive to the changes of wheel-rail contact parameters, which can be caused by the wear of wheel tread and rail head, as well as the changes of parameters such as rail cant and gauge, and it also represents that the vehicle has a better track adaptability and longer period of turning repair and track grinding, reducing costs of the vehicle operation and maintenance. Fig. 9 shows the suspension parameters design results for the Third Condition in single-objective analysis. As shown in the Fig., Fig. 9(a) is composed of 137 polylines, which means that there are 137 groups of parameter sets satisfying the threshold of equivalent conicity robustness index $\operatorname{std}\left(\zeta_{\lambda}\right)$. Fig. $9(\mathrm{~b})$ is the distribution of valid suspension parameters for the Third Condition. No matter what other suspension parameters take, it is necessary to select a value of $\operatorname{cs} x$ within the range of Min to guarantee the equivalent conicity robustness stability of vehicles, while the values of other suspension parameters distributions can be chosen within the ranges of five segments corresponding to each other, which means that other parameters can achieve a strong equivalent conicity robustness in a wide range of combinations when the value of $\operatorname{cs} x$ is selected in the range of Min. Besides, the polylines $s 5$ and $s 6$ in Fig. 9(a) are selected as two groups of typical suspension parameter sets for the

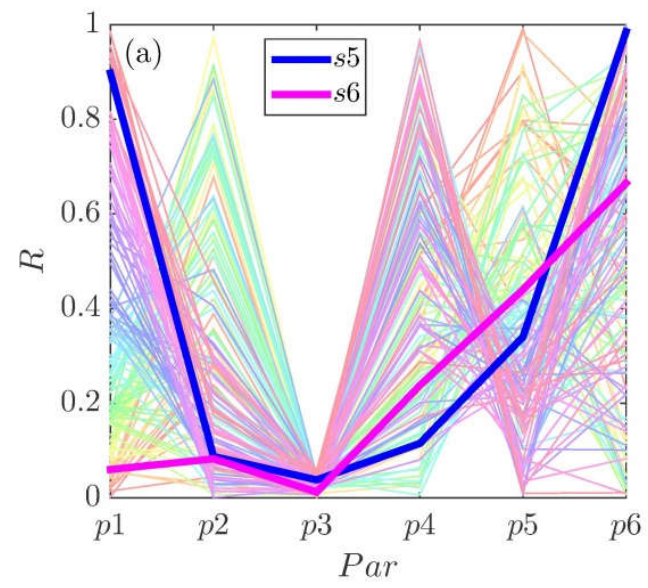

subsequent dynamic performance analysis.

On the other hand, the method of discrete statistics is utilized to analyze the matching rules of suspension parameters. Fig. 10 is a three-dimensional histogram showing the number of valid suspension parameter sets. It can be drawn that, when kncsx chooses a value within the range of Small, the combination of $k p x$ and csy in a wide range can satisfy the requirements of equivalent conicity robustness. When the value of kncsx is selected in the range of Small, the selection of the values of both csy and $k p x$ within the respective range of Large is required to ensure the equivalent conicity robustness. In short, as the value of kncsx increases, the values of both $k p x$ and csy demand to be decreased.

\section{Stability analysis}

Aiming at the 6 groups of typical suspension parameter sets for each single-objective analysis, the vehicle linear stability analysis is carried out. For instance, the root locus curves corresponding to the variety of vehicle running speed and equivalent conicity for the typical suspension parameter sets are obtained, and the corresponding linear stability index for each group is researched. Table 3 shows the values of the 6 groups of typical suspension parameter sets and their calculated robust stability indexes respectively. The 6 groups of typical suspension parameter sets are represented by $s 1 \sim s 6$.

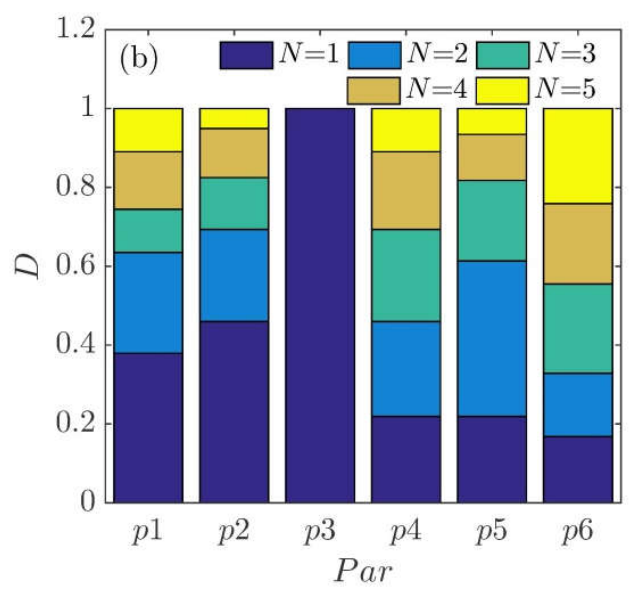

Fig. 9. Parameters matching and distribution for equivalent conicity robustness 

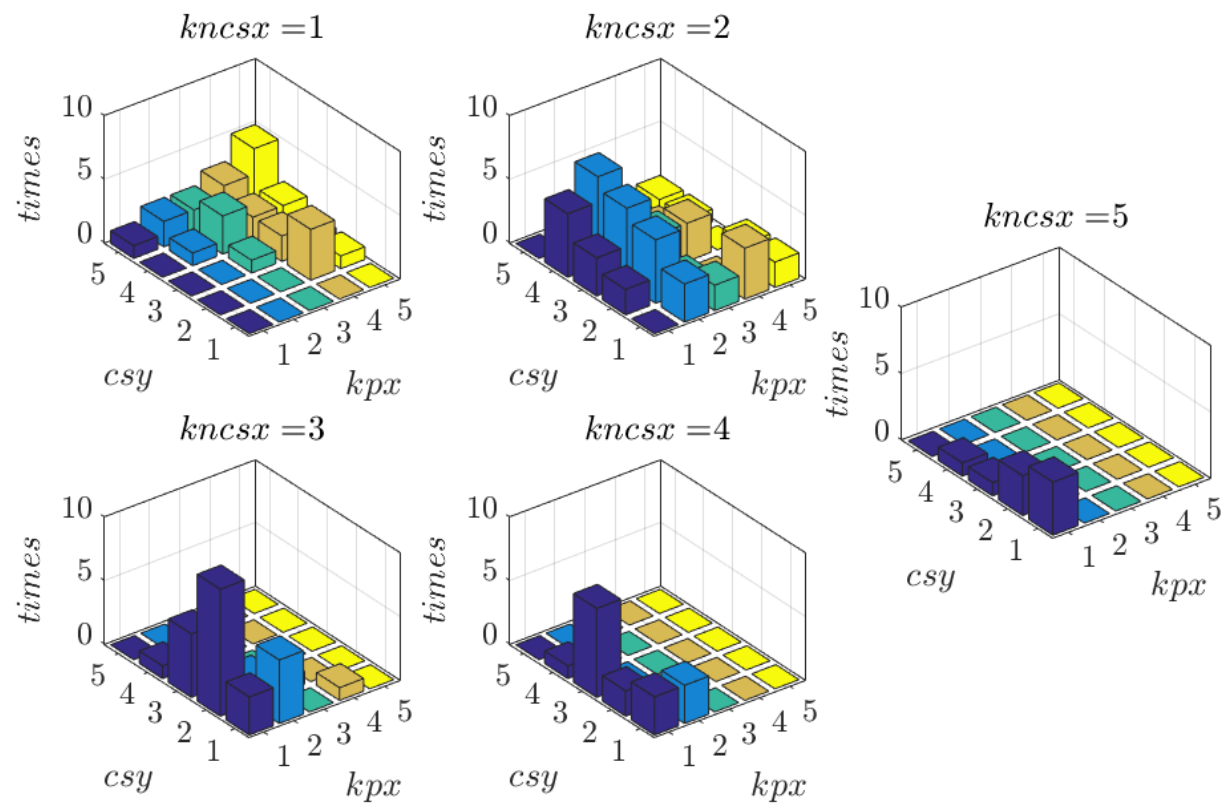

Fig. 10. Parameter matching of $k p x, c s y$ and $k n c s x$ for equivalent conicity robustness

Table 3. Typical parameter sets and robust stability indexes

\begin{tabular}{|c|c|c|c|c|c|c|c|c|c|c|}
\hline \multirow{2}{*}{ Set } & \multirow{2}{*}{$\begin{array}{c}k p x \\
(\mathrm{kN} / \mathrm{mm})\end{array}$} & \multirow{2}{*}{$\begin{array}{c}k p y \\
(\mathrm{kN} / \mathrm{mm})\end{array}$} & \multirow{2}{*}{$\begin{array}{c}\operatorname{cs} x \\
(\mathrm{kN} \mathrm{s} / \mathrm{m})\end{array}$} & \multirow{2}{*}{$\begin{array}{c}c s y \\
(\mathrm{kN} \mathrm{s} / \mathrm{m})\end{array}$} & \multirow{2}{*}{$\begin{array}{c}\text { kncsx } \\
(\mathrm{kN} / \mathrm{mm})\end{array}$} & \multirow{2}{*}{$\begin{array}{c}k n c s y \\
(\mathrm{kN} / \mathrm{mm})\end{array}$} & \multicolumn{4}{|c|}{ Robust stability indexes } \\
\hline & & & & & & & $\zeta_{\text {low }}$ & $\zeta_{\text {norm }}$ & $\operatorname{std}\left(\zeta_{p a r}\right)$ & $\operatorname{std}\left(\zeta_{\lambda}\right)$ \\
\hline$s 1$ & 88.4 & 5.92 & 4,009 & 43.6 & 6.67 & 15.4 & -0.25 & -0.24 & 0.04 & 0.11 \\
\hline$s 2$ & 12.9 & 9.10 & 3,536 & 38.1 & 10.8 & 22.4 & -0.28 & -0.25 & 0.04 & 0.13 \\
\hline$s 3$ & 13.6 & 4.88 & 4,629 & 15.4 & 12.3 & 22.5 & -0.06 & -0.25 & 0.03 & 0.07 \\
\hline$s 4$ & 81.1 & 4.27 & 405.0 & 40.8 & 5.88 & 19.7 & -0.09 & -0.19 & 0.03 & 0.04 \\
\hline$s 5$ & 90.8 & 4.05 & 478.5 & 14.6 & 11.8 & 24.7 & -0.05 & -0.17 & 0.04 & 0.04 \\
\hline$s 6$ & 15.4 & 3.99 & 358.4 & 19.5 & 13.8 & 18.3 & -0.14 & -0.22 & 0.04 & 0.05 \\
\hline
\end{tabular}

For $s 1$ and $s 4$, the value of kncsx within the range of Small is required to fulfill the vehicle performance index. However, in the actual engineering structure, the rubber joint with too small stiffness cannot be realized due to design problems such as strength and fatigue. Hence, the two groups of suspension parameter sets are only considered to be theoretically feasible, and there is no discussion on them. Besides, a value of $\operatorname{cs} x$ within the range of Large matching to a value of $k p x$ within the range of Small is adopted by $s 2$ and $s 3$, whose suspension parameters matching mode is defined as Type 1 . A value of $\operatorname{cs} x$ within the range of Small is employed by $s 5$ and $s 6$, whose parameters matching mode is defined as Type 2. Compared with $s 3, s 2$ utilizes a larger value of $c s y$, and its low conicity hunting stability is better, but the equivalent conicity robustness of $s 2$ is deteriorated. Comparing $s 5$ to $s 6$, they all select a value of $\operatorname{cs} x$ within the range of Small and have a better equivalent conicity robustness. Nevertheless, $s 6$ utilizes a smaller value of $k p x$ than $s 5$, whose low concity stability and normal concity stability of the corresponding vehicle system are better than $s 5$. In conclusion, the design principles for the two types of suspension parameters matching modes are different. Type 1 employs a larger running stability margin to compensate for the lack of the equivalent conicity robustness, while Type 2 adopts better equivalent conicity robustness with an appropriate hunting stability of vehicles. The two types of parameters matching modes are both applied in practical engineering.

The root loci of the vehicle system with the change of running speed according to the 6 groups of suspension parameter sets are shown in Fig. 11. Each root locus is composed of 40 sets of characteristic roots in speed range of 20 $800 \mathrm{~km} / \mathrm{h}$, and each ' + ' indicates a corresponding mode. The larger symbol represents a larger running speed. The horizontal axis indicates the mode damping ratio $\zeta$ (negative sign indicates a stable value), which is 
the ratio of the real part to the modulus of eigenvalues of the system matrix. The vertical axis indicates the damped vibration frequency of mode, which is the imaginary part of eigenvalues. Normally, as the speed increases, the hunting-related mode's damping reduces. When the $\zeta$ is greater than 0 , the hunting movement is unstable. Mostly, the low-frequency hunting mode $(1-5 \mathrm{~Hz})$ determines the vehicle hunting critical speed.

Comparing the speed root locus of the vehicle system with the 6 groups of suspension parameter sets, it can be found that the root locus curve is consistent with the classification of the suspension parameters mode. The Type 1 adopts the rule that a smaller kpx matches a larger csx, and the stability of the bogie hunting mode with frequency below $2 \mathrm{~Hz}$ is enhanced with the increasing of vehicle speed, such as the suspension parameters of $s 2$ and $s 3$. The Type 2 adopts a smaller csx, with which the hunting modes with frequency range of $1 \sim 4 \mathrm{~Hz}$ affects the linear stability of the vehicle system. The stability of the bogie hunting mode decreases with the increase of the vehicle speed, such as the suspension parameters of $s 5$ and $s 6$.

The root loci of the vehicle system with the change of equivalent conicity according to the 6 groups of suspension parameter sets are shown in Fig. 12, in which the vehicle running speed is $350 \mathrm{~km} / \mathrm{h}$. Each root locus curve is composed of 25 sets of characteristic roots in the equivalent conicity range of $0.02-0.5$, and each ' 0 ' indicates a corresponding mode. The larger symbol represents a larger equivalent conicity. The horizontal axis indicates the mode damping ratio $\zeta$ (negative sign indicates a stable value), which is the ratio of the real part to the modulus of eigenvalues of the system matrix. The vertical axis indicates the damped vibration frequency of the mode, which is the imaginary part of eigenvalues. When the $\zeta$ is greater than 0 , the hunting movement is unstable. Normally, as the equivalent conicity increases, the hunting-related mode damping increases first and then decreases.
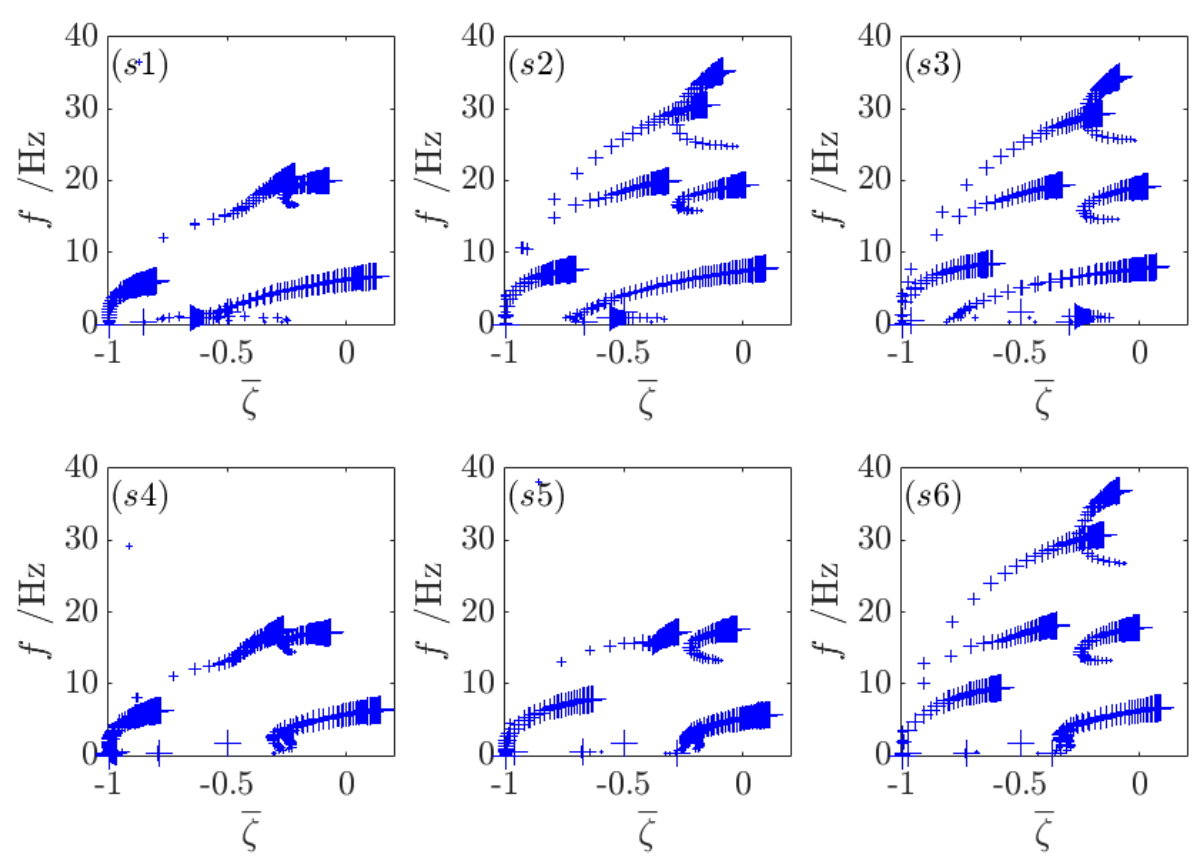

Fig. 11. Root loci of the vehicle with the changes of speed

In the figure, when the normal equivalent conicity of the vehicle is located at the turning position of the bogie hunting root locus, the equivalent conicity robustness index of the vehicle is small. The small vehicle equivalent conicity robustness index indicates that the hunting stability is insensitive to the variation of the wheel-rail contact equivalent conicity. In other words, the vehicle has a strong adaptability to the track variation, such as the variable rail cant and rail head profile, as well as a long repair period for the tread, which reduces the costs of vehicles operation and maintenance. It is observed from the figure. that the stability of 
vehicles corresponding to the suspension parameter sets of $s 4, s 5$ and $s 6$ is less affected by the variation of the equivalent conicity. In fact, the vehicle hunting instability due to the low wheel-rail contact equivalent conicity occurs occasionally, especially in the situation of a new tread profile or a larger rail cant. By means of increasing the vehicle hunting stability, the equivalent conicity robustness and the system stability with low equivalent conicity of the vehicle are better, such as the suspension parameter sets of $s 2$. But the excessive stability margin will reduce the lateral displacement of the wheel-rail contact point, resulting in the local tread wear easily.

In order to analyze the system hunting stability of the vehicle corresponding to the 6 groups of suspension parameter sets in Table 3 , the linear stability index of the vehicle with the variation of equivalent conicity and running speed is calculated as shown in Fig. 13. It can be observed from the graphs that the change of the running speed has a little effect on the hunting stability when the variation range of the stability index along the longitudinal axis is small, which suggests that the system has a strong hunting stability with the change of running speed. The influence of the running speed on the vehicle stability with low equivalent conicity is smaller than the vehicle with high equivalent conicity. When the stability index changes little along the abscissa axis, the equivalent conicity robustness of the vehicle is better. It can be drawn from the figure that the stability of the vehicle adopting the 6 groups of suspension parameter sets has significantly different effects with the variation of the equivalent conicity and running speed.
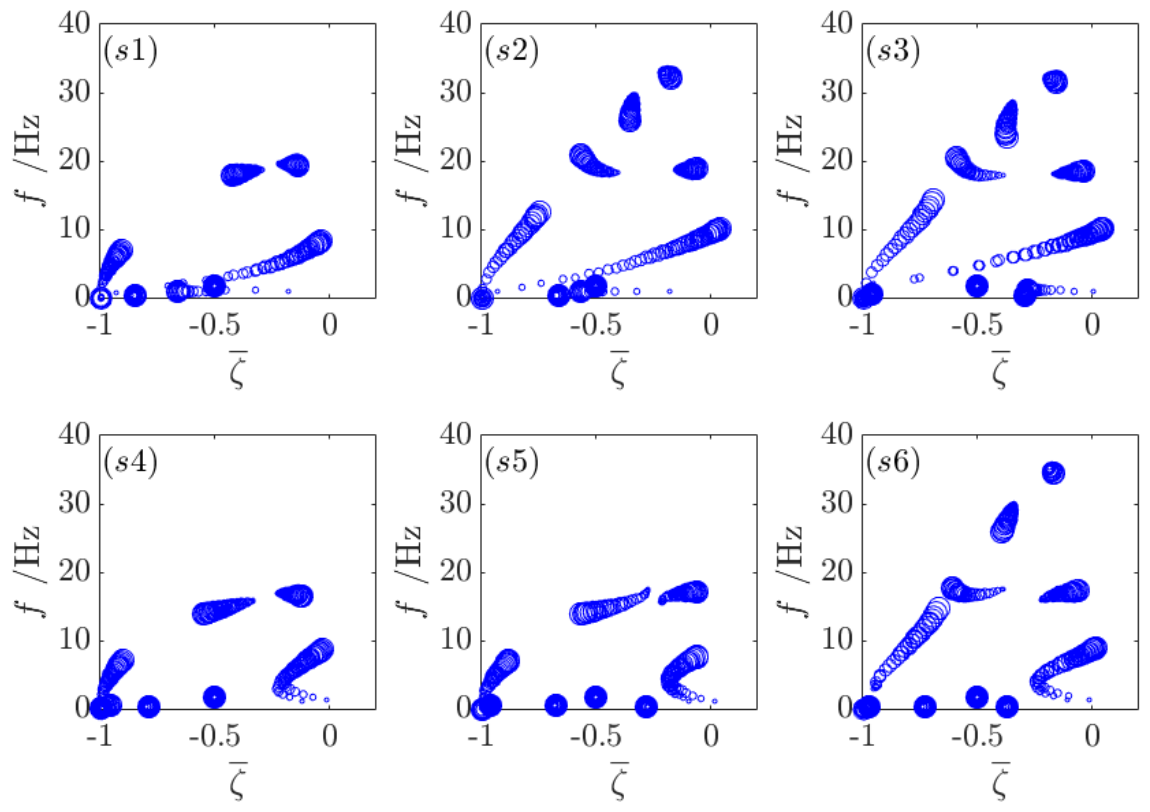

Fig. 12. Root loci of the vehicle with the changes of equivalent conicity

The contour of the vehicle linear stability index is also consistent with the classification of suspension parameter modes. For the suspension parameters matching of Type 1, there are larger stability margins for $s 1$ and $s 2$. However, $s 3$ has a poor stability at low equivalent conicity. The vehicle stability decreases with the increase of equivalent conicity at the speed of $350 \mathrm{~km} / \mathrm{h}$. In addition, there is a sufficient stability at the condition of low equivalent conicity. For the Type 1, it needs to match a smaller equivalent conicity to ensure the vehicle hunting stability. The stability margins of $s 5$ and $s 6$ are smaller, but the system stability is less affected by the variation of the vehicle running speed and equivalent conicity. The vehicle stability increases with the increase of equivalent conicity at the condition of larger equivalent conicity. When the vehicle adopts the suspension parameter set of Type 2, a larger equivalent conicity tread is needed to ensure the vehicle hunting stability. No matter which type of suspension parameter sets is adopted, the system stability will become worse if the equivalent conicity of wheel-rail contact is too small. 

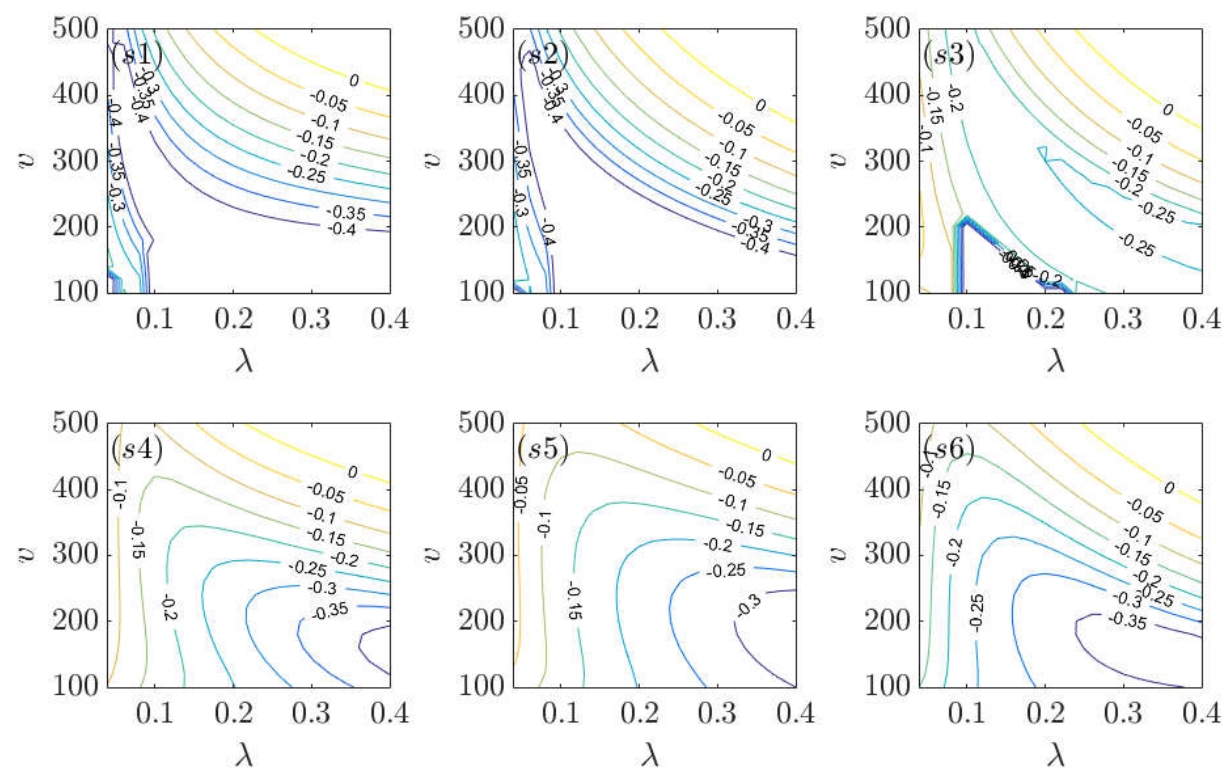

Fig. 13. The contour of stability index with different speeds and equivalent conicities

\section{Conclusion}

(1) The concept of robust hunting stability is proposed, and the suspension parameter robustness and equivalent conicity robustness for vehicle system are defined. Based on the robustness indexes as well as the stability indexes of the vehicle with a wider range of equivalent conicity, the key bogie suspension parameters matching rules affecting the vehicle hunting stability are analyzed. Design of Experiments (DOE) is used to search the suspension parameters from a large number of combined random suspension parameters to satisfy the defined robust hunting stability indexes. The vehicle system has a robust hunting stability by adopting the optimized suspension parameters to improve the adaptability for the variation of suspension parameters, tread profile, as well as track, such as the variable rail cant and rail head profile, in a wide speed range.

(2) The method of discrete statistical analysis is utilized to summarize the matching rules of suspension parameters for improving the three single-objective performances respectively. Moreover, the two types of bogie suspension parameters matching modes are obtained. The first type adopts a smaller longitudinal stiffness combined with a larger yaw damper. The second type employs a smaller yaw damper, but the damping of secondary lateral damper and the longitudinal stiffness of primary suspension demand to have a negative correlation with joint stiffness of yaw damper. Besides, the first type of suspension parameters matching mode requires a smaller equivalent conicity to match, which has better low conicity stability. The second type of suspension parameters matching mode requires a larger equivalent conicity to match, and the vehicle has better equivalent conicity robustness. Both suspension parameters matching modes can achieve a better suspension parameter robustness of the vehicle system.

\section{References}

[1] YAO Yuan, LI Guang, SARDAHI Y, et al. Stability enhancement of a high-speed train bogie using active mass inertial actuators. Vehicle System Dynamic, 2019, 57(3):389-407.

[2] YAO Yuan, WU Guosong, SARDAHI Y, et al. Hunting stability analysis of high-speed train bogie under the frame lateral vibration active control. Vehicle System Dynamic, 2018, 56(2):297-318.

[3] ZHANG Xiaoxia, WU Guosong, LI Guang, YAO Yuan. Actuator optimal placement studies of high-speed power bogie for active hunting stability. Vehicle System Dynamic, 2020, 58(1): 108-122.

[4] GOODALL R M, KORTUEM W. Mechatronic developments for railway vehicles of the future. Control Engineering Practice. 2002, 10(8):887-898.

[5] PEARSON J T, GOODALL R M, MEI T X, et al. Active stability control strategies for a high speed bogie. Control Engineering Practice, 2004, 12(11):1381-1391.

[6] MEI T X, GOODALL R M. Stability control of railway bogies using absolute stiffness: sky-hook spring approach. Vehicle System Dynamic. 2006, 44(sup):83-92. 
[7] JIANG J Z, MATAMOROS-SANCHEZ A Z, GOODALL $\mathrm{R} \quad \mathrm{M}$, et al. Passive suspensions incorporating inerters for railway vehicles. Vehicle System Dynamic. 2012, 50(sup):263-276.

[8] BRUNI S, GOODALL R M, MEI T X, et al. Control and monitoring for railway vehicle dynamics. Vehicle System Dynamic. 2007, 45(7-8):743-779.

[9] HE Y, MCPHEE J. Multidisciplinary Optimization of Multibody Systems with Application to the Design of Rail Vehicles[J]. Multibody System Dynamics, 2005, 14(2): 111-135.

[10] JOHNSSON A, BERBYUK V, ENELUND M. Pareto optimisation of railway bogie suspension damping to enhance safety and comfort[J]. Vehicle System Dynamics, 2012, 50(9):1379-1407.

[11] BIDELEH S M, BERBYUK V, PERSSON R. Wear/comfort Pareto optimisation of bogie suspension[J]. Vehicle System Dynamics, 2016, 54(8):1053-1076.

[12] BIDELEH S M. Robustness analysis of bogie suspension components Pareto optimised values[J]. Vehicle System Dynamics, 2017, 55(8):1189-1205.

[13] NEJlAOUI M , HOUIDI A, AFFI Z , et al. Multiobjective robust design optimization of rail vehicle moving in short radius curved tracks based on the safety and comfort criteria[J]. Simulation Modelling Practice and Theory, 2013, 30(3): 21-34.

[14] ZHAO Ziyan. Research on the Application and Structural Optimization Design Method Based on DOE and Surrogate Model[D]. Xian: Xi'an University of Architecture and Technology, 2017. (in Chinese)

[15] LI Xiang, REN Zunsong, XU Ning. Dynamic performance analysis of high-speed vehicle based on optimization of bogie suspension parameters and tread conicity. Journal of the China Railway Society, 2018, 40(3):39-44. (in Chinese)

[16] HE Y, MCPHEE J. Design optimization of rail vehicles with passive and active suspensions: A combined approach using genetic algorithms and multibody dynamics, Vehicle System Dynamic, 2002, 37(Suppl.): 397-408.

[17] HE Y, MCPHEE J. Optimization of the lateral stability of rail vehicles. Vehicle System Dynamic, 2002, 38(5): 361-390.

[18] YAO Yuan, ZHANG Xiaoxia, ZHANG Hongjun, et al. The stability mechanism and its application to heavy haul couplers with arc surface contact. Vehicle System Dynamic, 2013, 51(9):1324-1341.

[19] KARIN N C, BERGGREN E G, KAYNIA A M, et al. A new method for estimation of critical speed for railway tracks on soft ground. International Journal Rail Transportation, 2018, 6(4):203-217.

[20] WU Shengchuan, Xu ZW, Liu YX, et al. On the residual life assessment of high-speed railway axles due to induction hardening. International Journal Rail Transportation, 2018, 6(4):218-232.

[21] YAO Yuan, LI Guang, WU Guosong, et al. Suspension parameters optimum of high-speed train bogie for hunting stability robustness[J]. International Journal Rail Transportation, 2020, 8(3): 195-214.

[22] ALONSO. Yaw damper modelling and its influence on the railway dynamic stability[J]. Vehicle System Dynamic, 2011, 49(8):1367-1387.
[23] ZHAI Wanming, LIU Pengfei, LIN Jianhui, et al. Experimental investigation on vibration behaviour of a $\mathrm{CRH}$ train at speed of $350 \mathrm{~km} / \mathrm{h}$. International Journal Rail Transportation, 2015, 3(1):1-16.

[24] GÖTZ G, POLACH O. Verification and validation of simulations in a rail vehicle certification context. International Journal Rail Transportation, 2018, 6(2):83-100.

[25] YAO Yuan, YAN Yapeng, HU Zhike, et al. The Motor Active Flexible Suspension and its Dynamic Effect on the High-speed Train Bogie. Journal of Dynamic Systems, Measurement, and Control, 2017, 140: 064501(1-7).

[26] YAO Yuan, ZHANG Xiaoxia, LIU Xu. The active control of the lateral movement of a motor suspended under a high-speed locomotive. Journal Rail Rapid Transit, 2016, 230(6):1509-1520.

[27] DEB K, AGRAWAL R B. Simulated binary crossover for continuous search space. Complex Systems, 1995, 9(2):115-148.

[28] YU Mengge, JIANG Rongchao, ZHANG Qian and ZHANG Jiye. Crosswind Stability Evaluation of High-Speed Train Using Different Wind Models. Chinese Journal of Mechanical Engineering, 2019, 32(1): 40 .

\section{Biographical notes}

LI Guang, born in1993, is currently a $\mathrm{PhD}$ candidate at State Key Laboratory of Traction Power, Southwest Jiaotong University, China.

E-mail:lg_4516@qq.com

YAO Yuan, born in1983, is currently a professor in State Key Laboratory of Traction Power, Southwest Jiaotong University, China. He has published more than $30 \mathrm{SCI}$ and EI retrieval papers. His research interests mainly included bogie design and theory, vehicle system dynamics and control and other fields of research work.

E-mail: yyuan8848@163.com

SONG Yadong, born in1996, is currently a $\mathrm{PhD}$ candidate at State Key Laboratory of Traction Power, Southwest Jiaotong University, China.

E-mail: 1176262508@qq.com

CHEN Guosheng, born in1966, is currently a professor-level senior engineer in CRRC Zhuzhou Electric Locomotive Co., Ltd.

E-mail: cgs5244@163.com

CHEN Kang, born in1963, is currently an associate professor in State Key Laboratory of Traction Power, Southwest Jiaotong University, China. His main research direction is vehicle system dynamics. E-mail: chenkang@home.swjtu.edu.cn 


\section{Declarations}

No potential conflict of interest was reported by the authors. The data sources and results in this paper are true and reliable, and the conclusion can be used to guide the matching design of high-speed train suspension parameters. The paper is completed with the support of the National Natural Science Foundation of China, Development and Verification Technology of Key
Components of Adaptive Bogie, the Independent Projects of Traction Power State Key Laboratory, and Research and Development project of China Railway Group. In the production process of the article, LI Guang and YAO Yuan simulate and analyze the data in this paper, SONG Yadong contributed to the translation, besides CHEN Guosheng and CHEN Kang corrected and checked the article carefully.

\section{Appendix}

Table 1. The vehicle model parameters.

\begin{tabular}{|c|l|c|}
\hline Symbol & \multicolumn{1}{|c|}{ Definition } & Value \\
\hline$m_{w}$ & Mass of the wheelset & $1639 \mathrm{~kg}$ \\
\hline$I_{w}$ & Yaw inertia of the wheelset & $822 \mathrm{~kg} \mathrm{~m}$ \\
\hline$m_{f}$ & Mass of bogie frame & $2328 \mathrm{~kg}$ \\
\hline$I_{f x}$ & Roll inertia of bogie frame & $2110 \mathrm{~kg} \mathrm{~m}$ \\
\hline$I_{f z}$ & Yaw inertia of bogie frame & $4080 \mathrm{~kg} \mathrm{~m}$ \\
\hline$m_{c}$ & Mass of carbody & $38936 \mathrm{~kg}$ \\
\hline$I_{c x}$ & Roll inertia of carbody & $1.67 \mathrm{e} 6 \mathrm{~kg} \mathrm{~m}$ \\
\hline$I_{c y}$ & Yaw inertia of carbody & $9.61 \mathrm{e} 5 \mathrm{~kg} \mathrm{~m}{ }^{2}$ \\
\hline$k_{p z}$ & Primary vertical stiffness per axle & $0.75 \mathrm{kN} / \mathrm{mm}$ \\
\hline$k_{s x}$ & Secondary longitudinal stiffness & $0.133 \mathrm{kN} / \mathrm{mm}$ \\
\hline$k_{s y}$ & Secondary lateral stiffness & $0.133 \mathrm{kN} / \mathrm{mm}$ \\
\hline$k_{s z}$ & Secondary vertical stiffness & $0.2 \mathrm{kN} / \mathrm{mm}$ \\
\hline$c_{s z}$ & Secondary vertical damper damping & $10 \mathrm{kN} \mathrm{s} / \mathrm{m}$ \\
\hline$c_{p z}$ & Primary vertical damper damping & $10 \mathrm{kN} \mathrm{s} / \mathrm{m}$ \\
\hline$k_{\phi}$ & Stiffness of anti-roll torsion bar & $4.15 \mathrm{MN} \mathrm{m} / \mathrm{rad}$ \\
\hline $2 l_{1}$ & Lateral spacing of primary suspension & $2000 \mathrm{~mm}$ \\
\hline$l_{b}$ & Length of axle box arm & $480 \mathrm{~mm}$ \\
\hline $2 b$ & Wheel base & $2500 \mathrm{~mm}$ \\
\hline $2 L$ & Length between bogie centers & $17375 \mathrm{~mm}$ \\
\hline $2 l_{0}$ & Distance of the contact spot & $1493 \mathrm{~mm}$ \\
\hline $2 l_{2}$ & Lateral spacing of the secondary suspension & $2200 \mathrm{~mm}$ \\
\hline$r_{0}$ & The wheel rolling radius & $460 \mathrm{~mm}$ \\
\hline$f_{\xi}$ & The longitudinal creep coefficient & $1 \mathrm{e} 7 \mathrm{~N}$ \\
\hline$f_{\eta}$ & The lateral creep coefficient & $1 \mathrm{e} 7 \mathrm{~N}$ \\
\hline$k_{r}$ & The contact stiffness of the wheel-rail & $0.05,0.17,0.30$ \\
\hline$\lambda_{e}$ & Wheel-rail contact conicity & Optimized \\
\hline$v$ & Running speed & Optimized \\
\hline$k p x$ & Primary longitudinal stiffness per axle & Optimized \\
\hline$k p y$ & Primary lateral stiffness per axle & Optimized \\
\hline$c s x$ & Yaw damper damping & Optimized \\
\hline$c s y$ & Secondary lateral damper damping & \\
\hline$k n c s x$ & Series stiffness of yaw damper damping & $350,500 \mathrm{~km}$ \\
\hline$k n c s y$ & Series stiffness of secondary lateral damper damping & \\
\hline & & \\
\hline
\end{tabular}




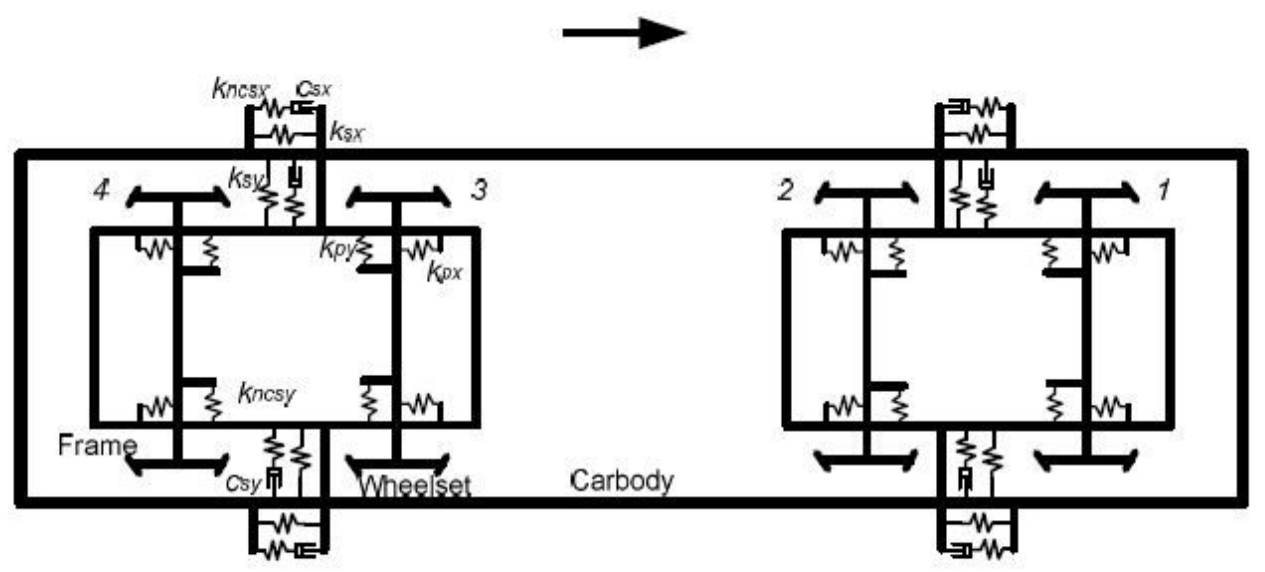

(a)

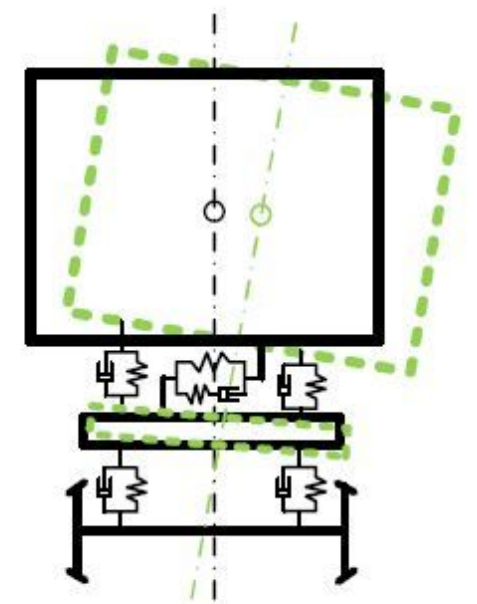

(b)

Figure 1

Simplified vehicle lateral dynamic model

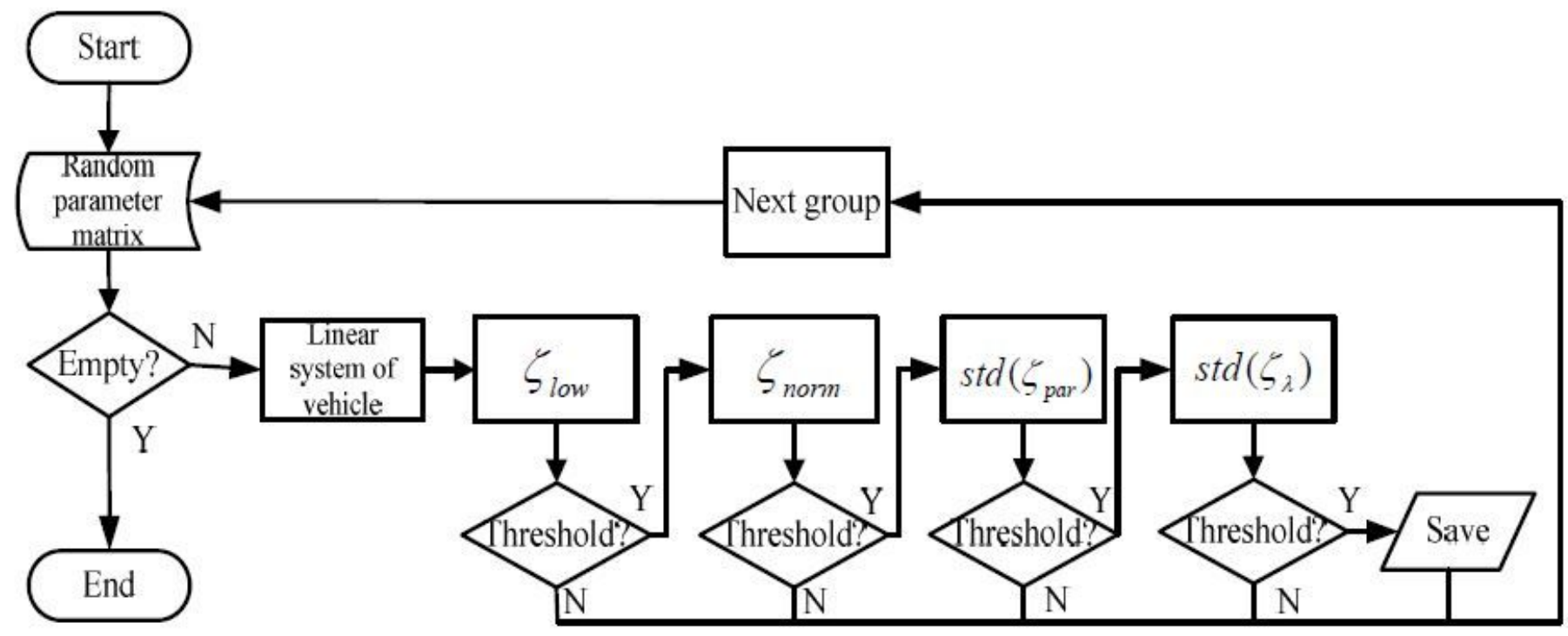

Figure 2

Design process of the suspension parameters 

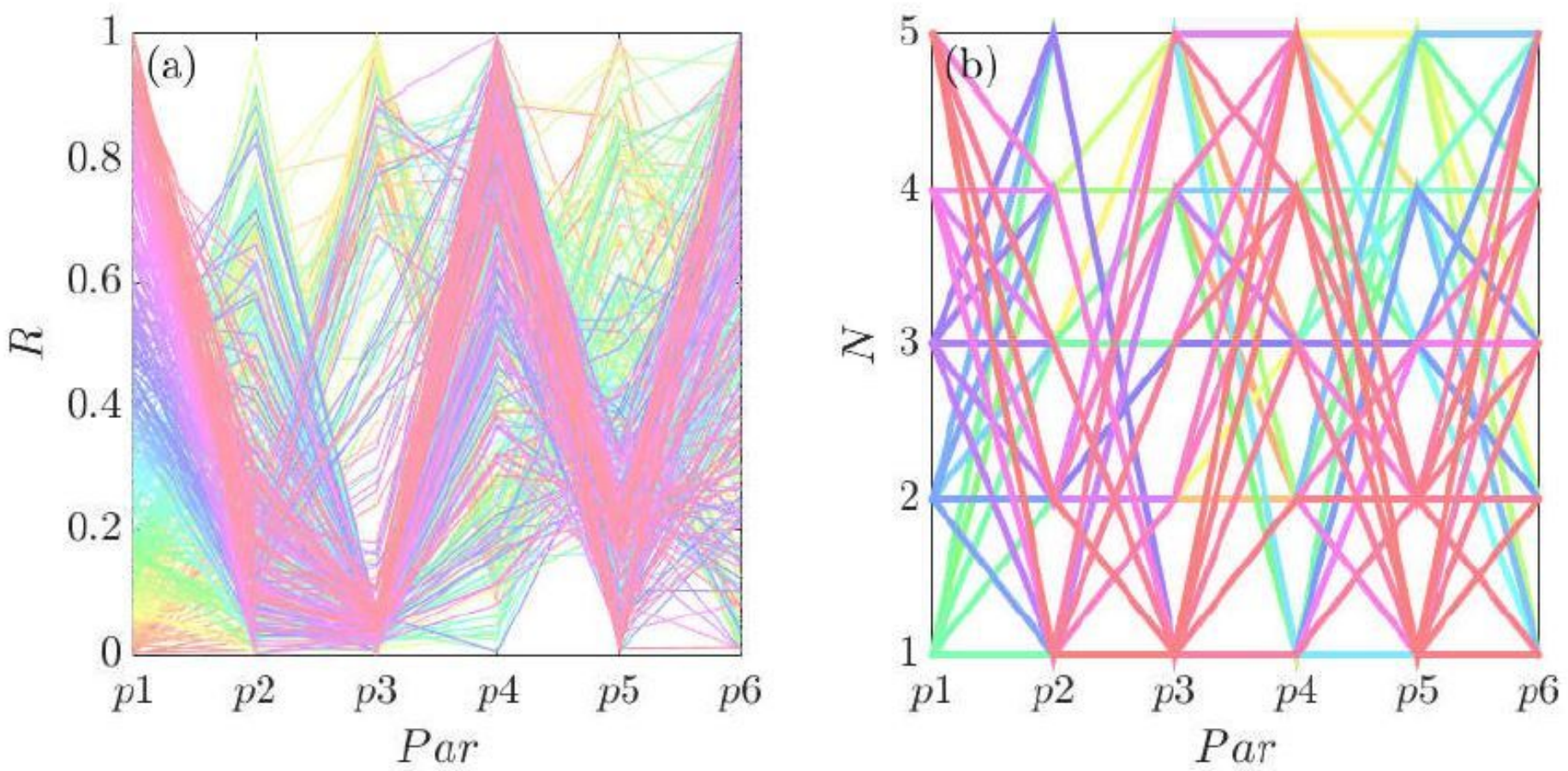

Figure 3

Design of regularization parameters and discrete statistics
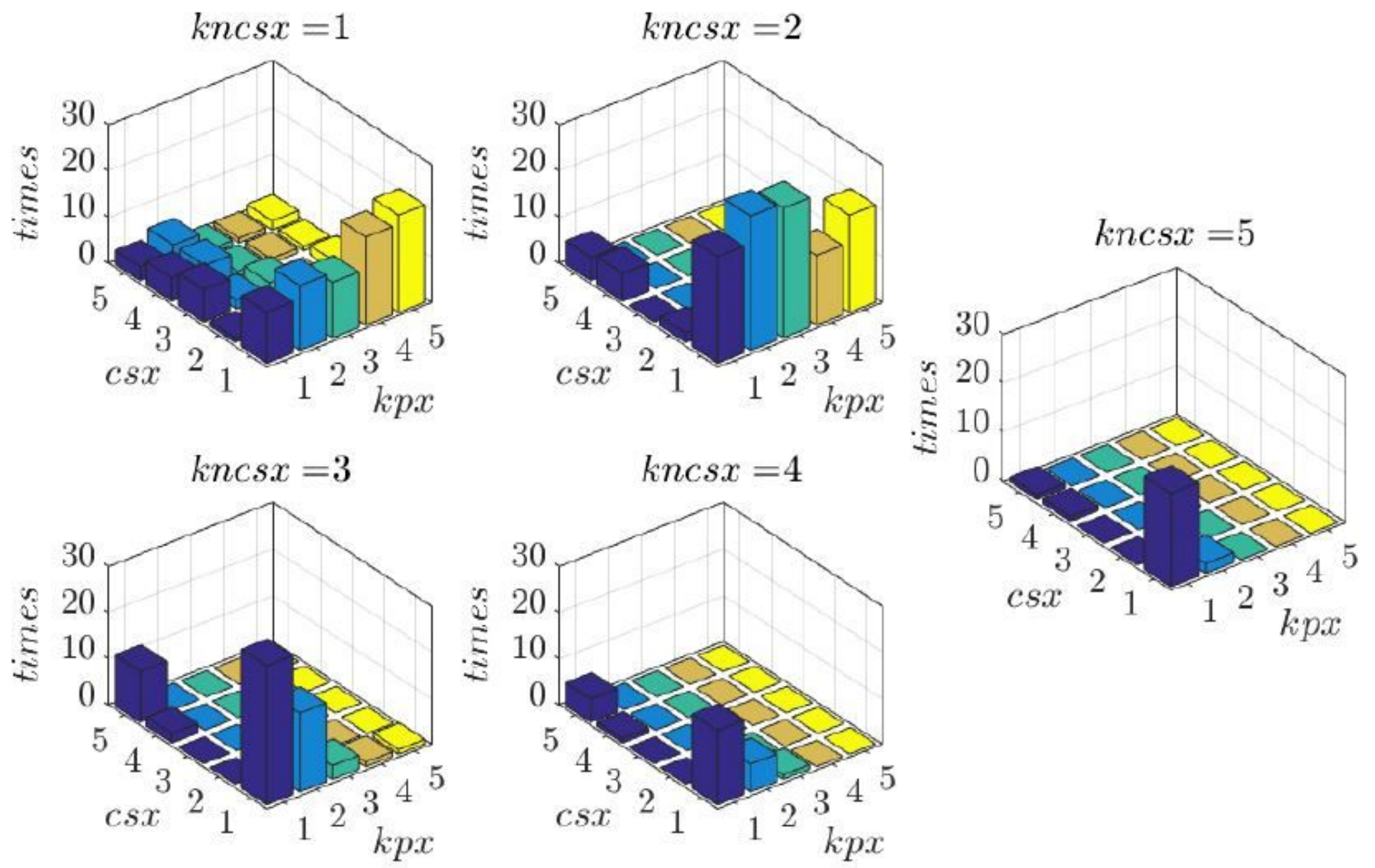
Figure 4

Parameters matching results of kpx, csx and kncsx
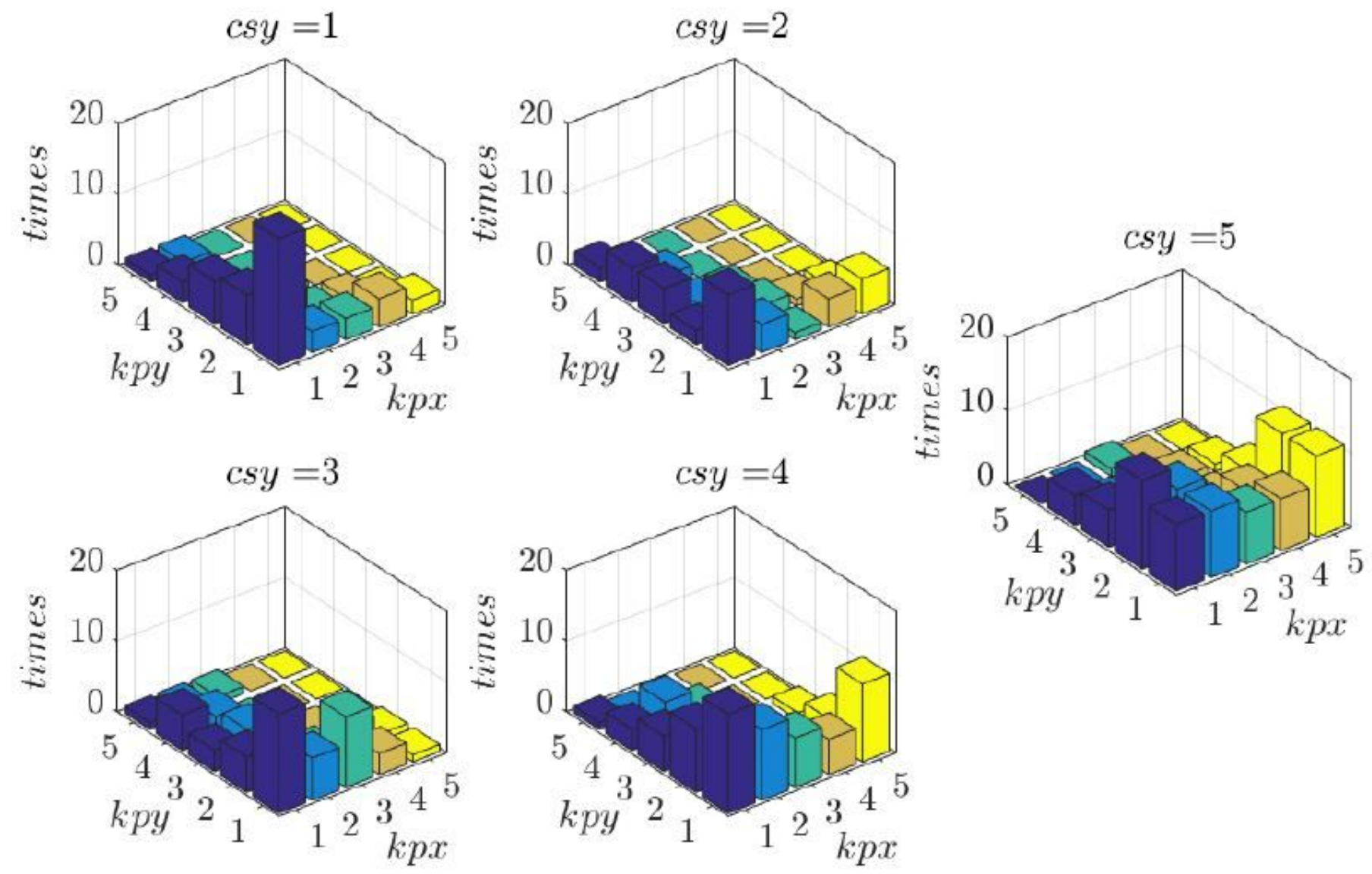

Figure 5

Parameters matching results of kpx, kpy and csy 

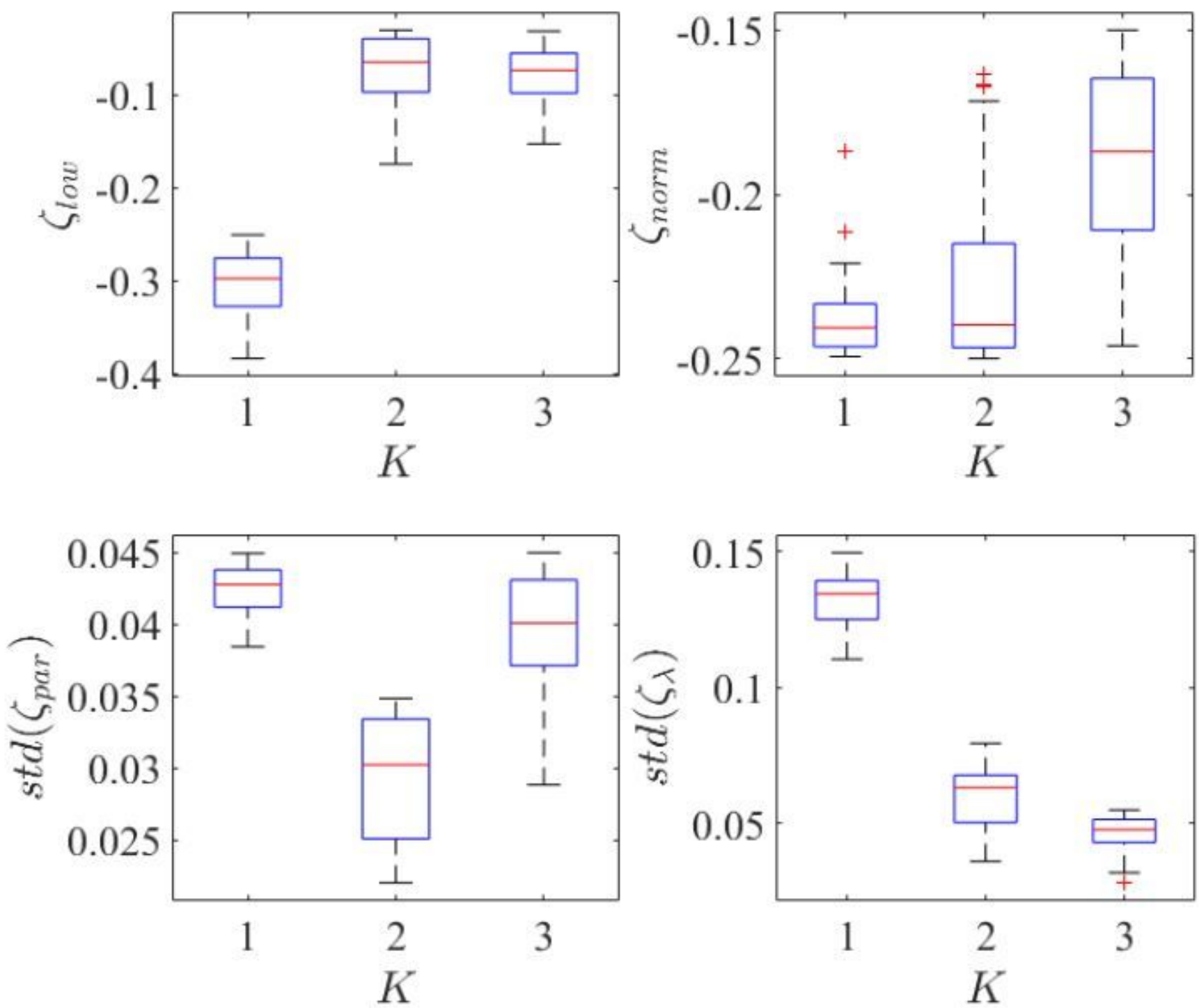

Figure 6

Distribution of index values of single-objective analysis 

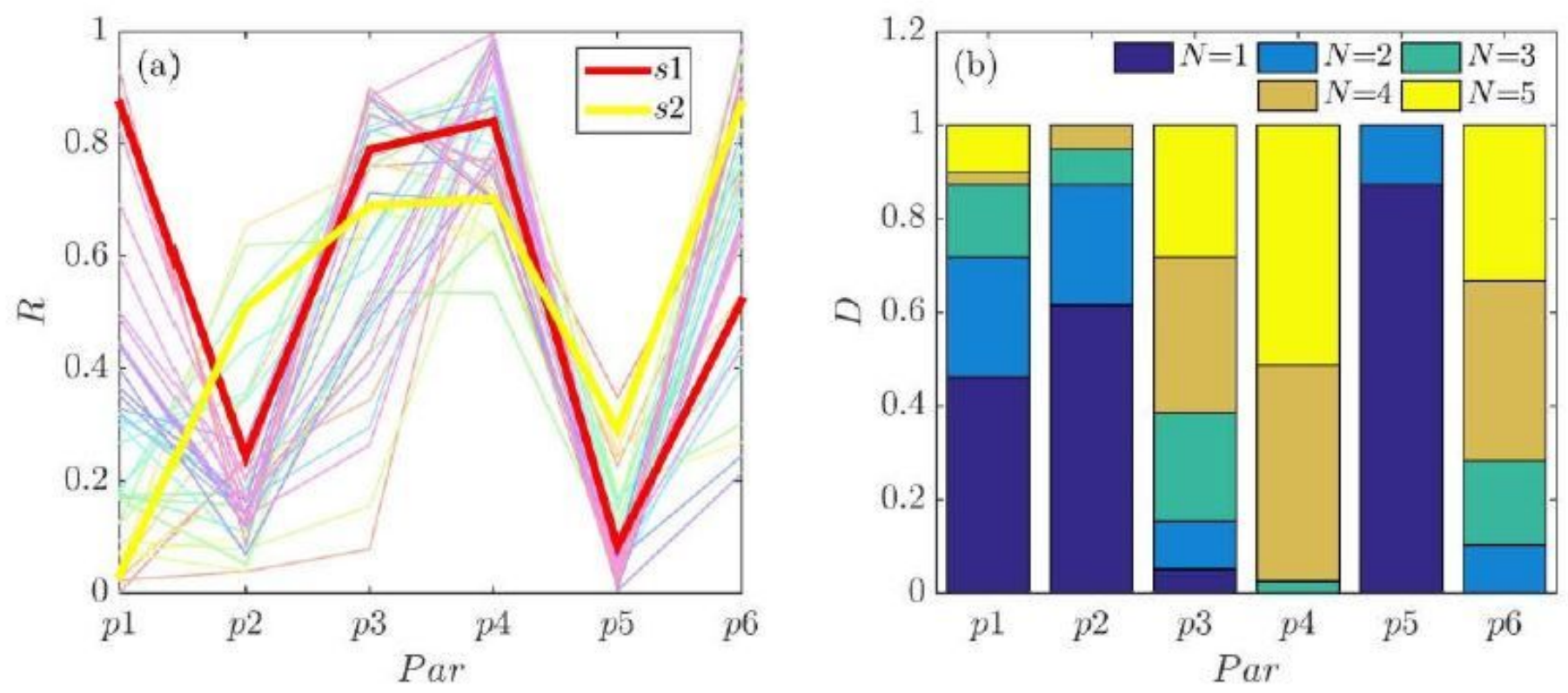

Figure 7

Parameters matching and distribution for low conicity stability
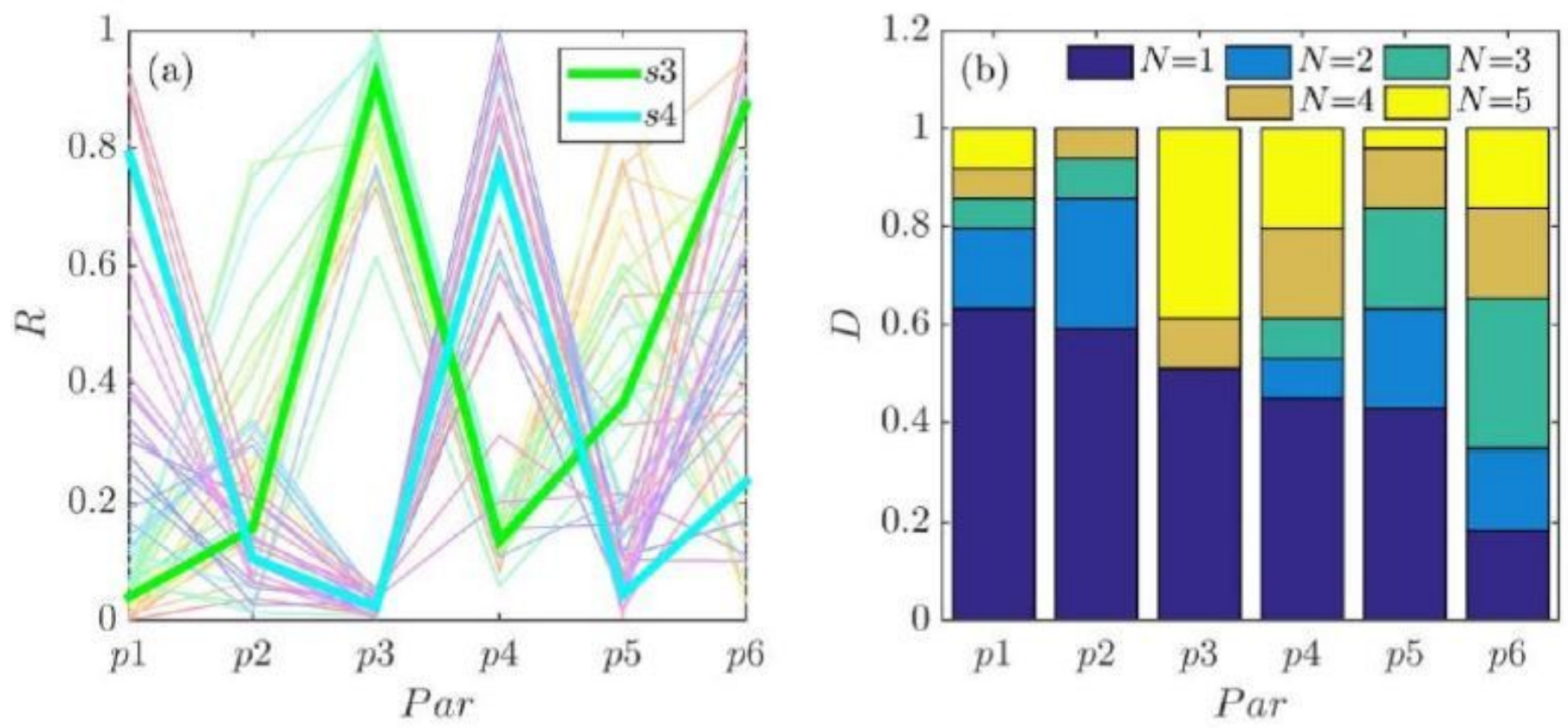

Figure 8

Parameters matching and distribution for suspension parameter robustness 

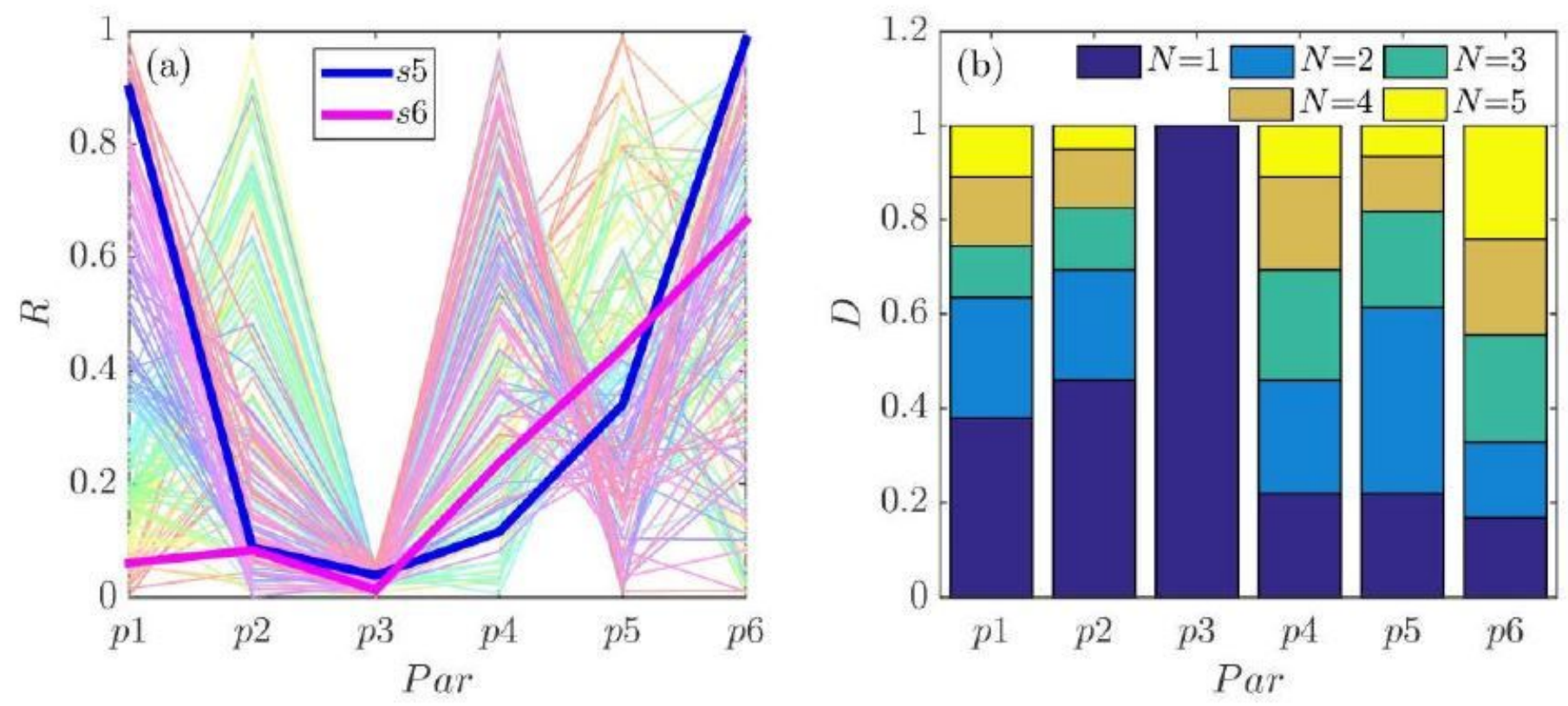

Figure 9

Parameters matching and distribution for equivalent conicity robustness
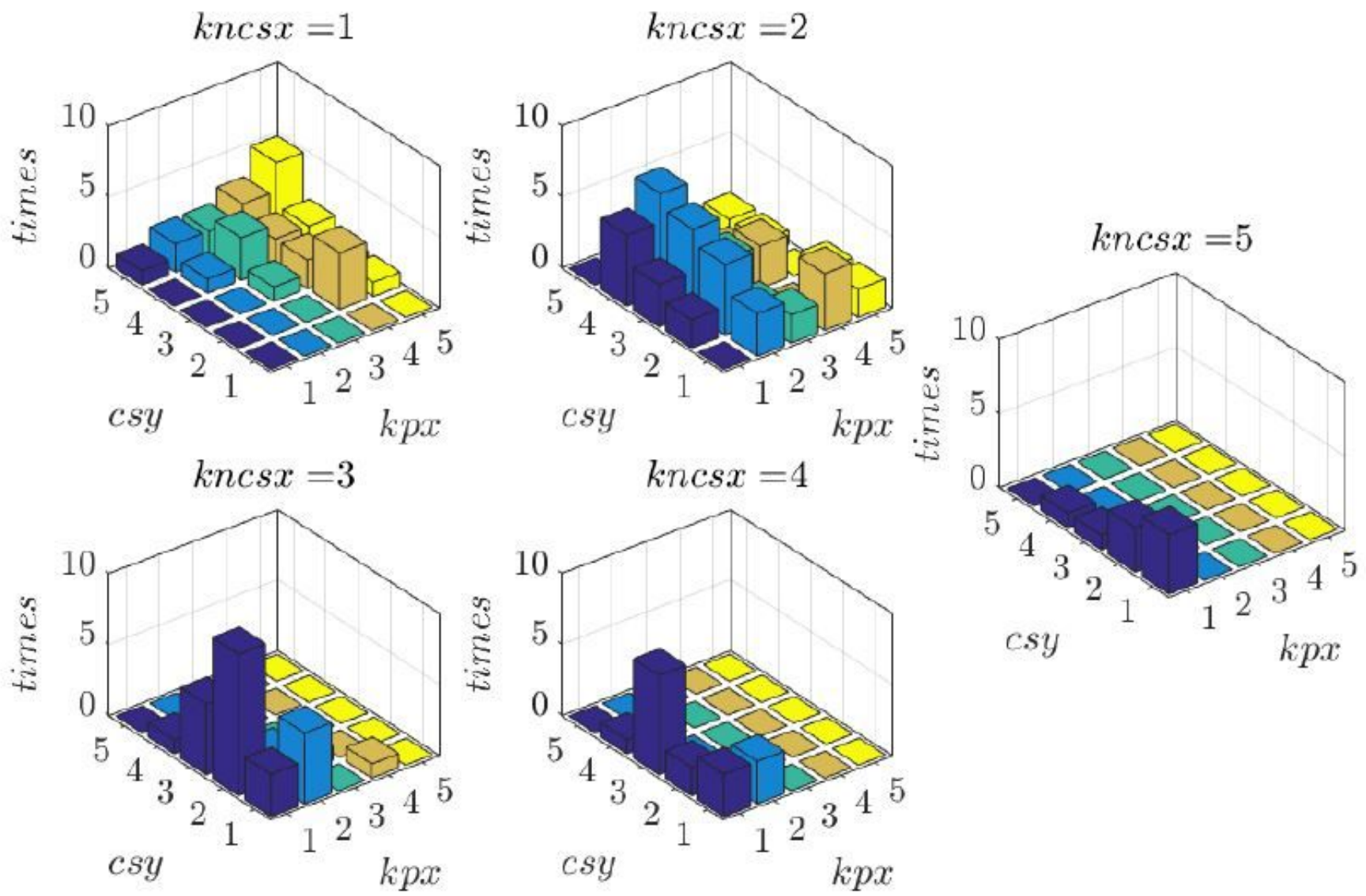

Figure 10 
Parameter matching of kpx, csy and kncsx for equivalent conicity robustness
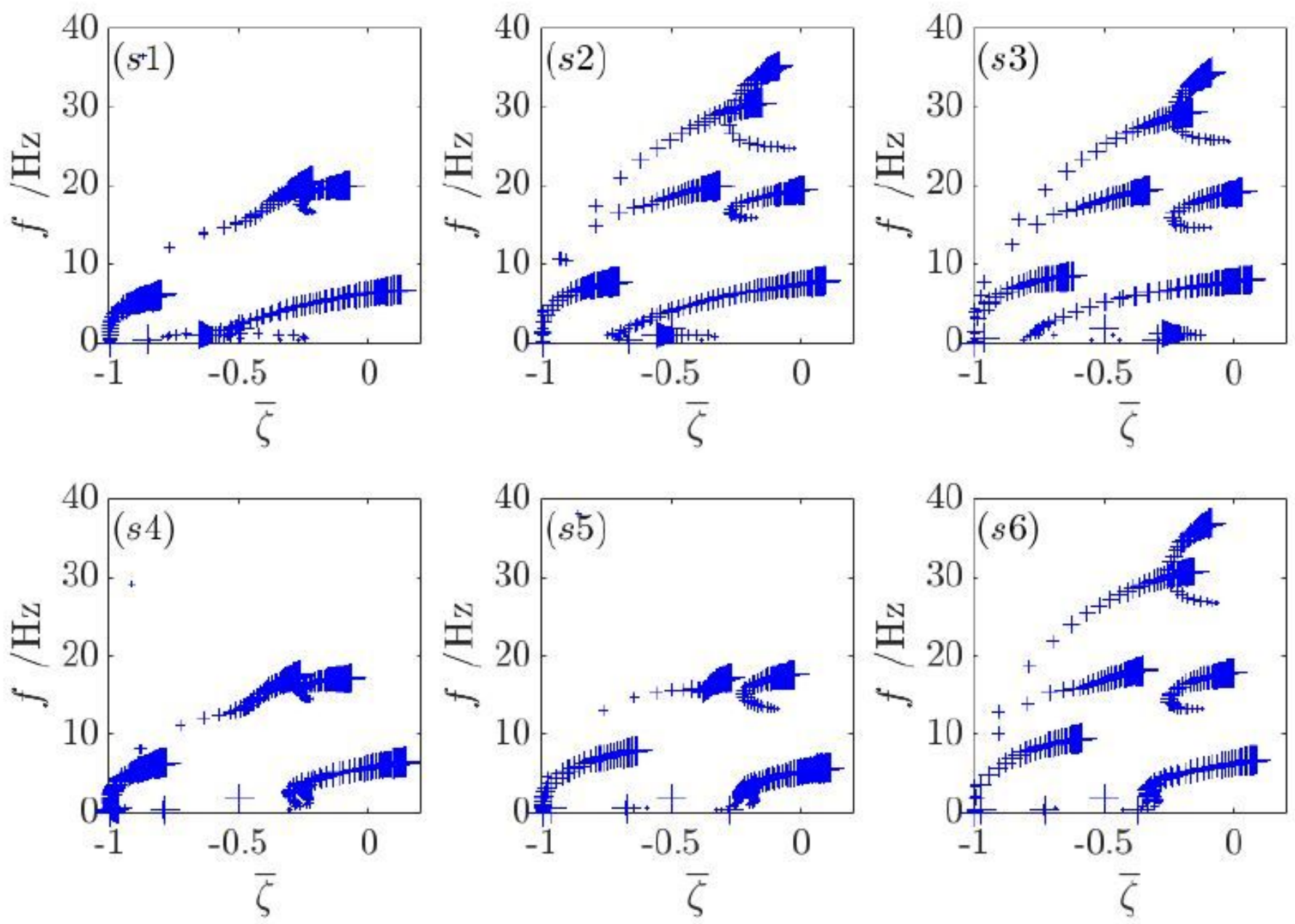

Figure 11

Root loci of the vehicle with the changes of speed 

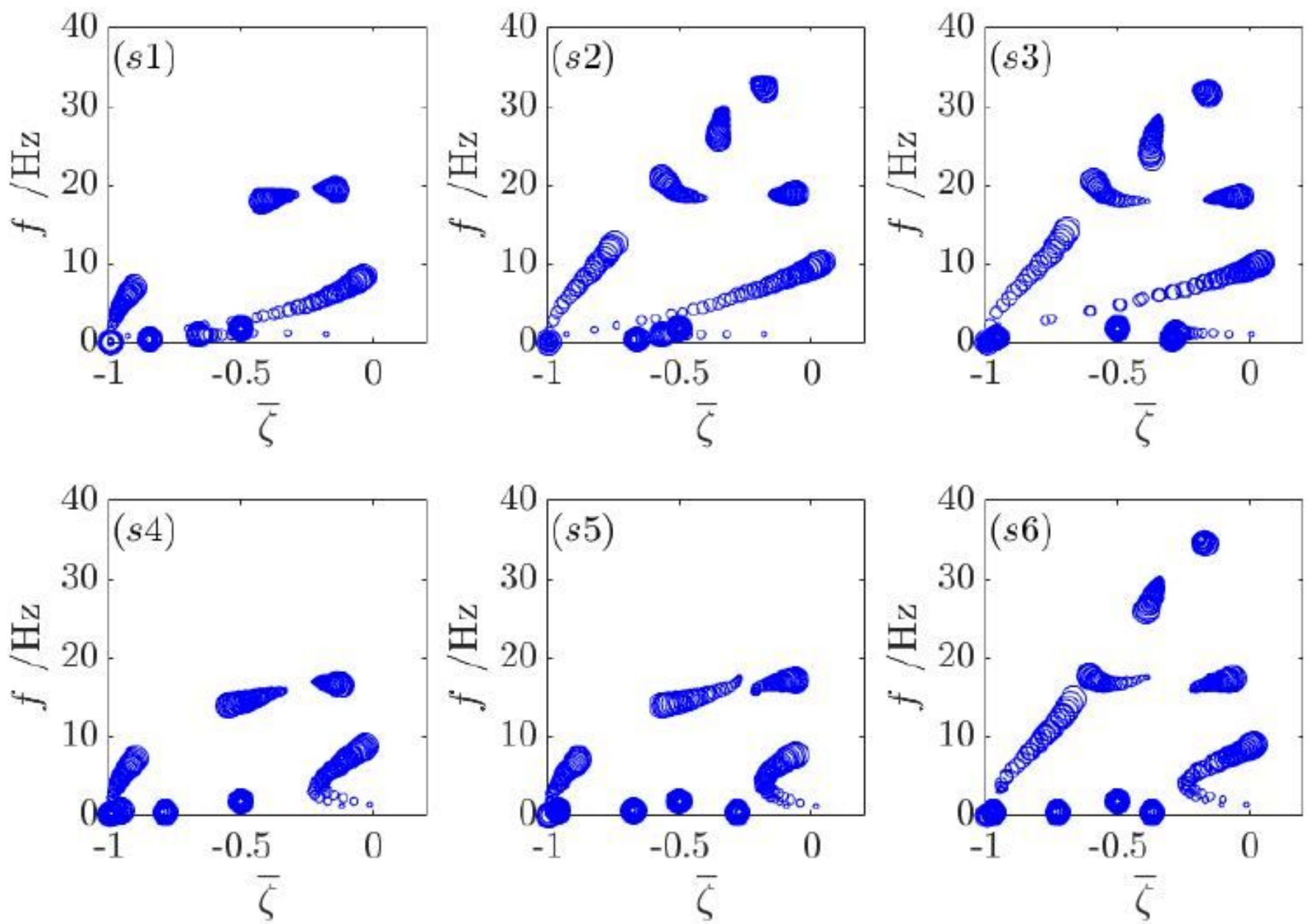

Figure 12

Root loci of the vehicle with the changes of equivalent conicity 

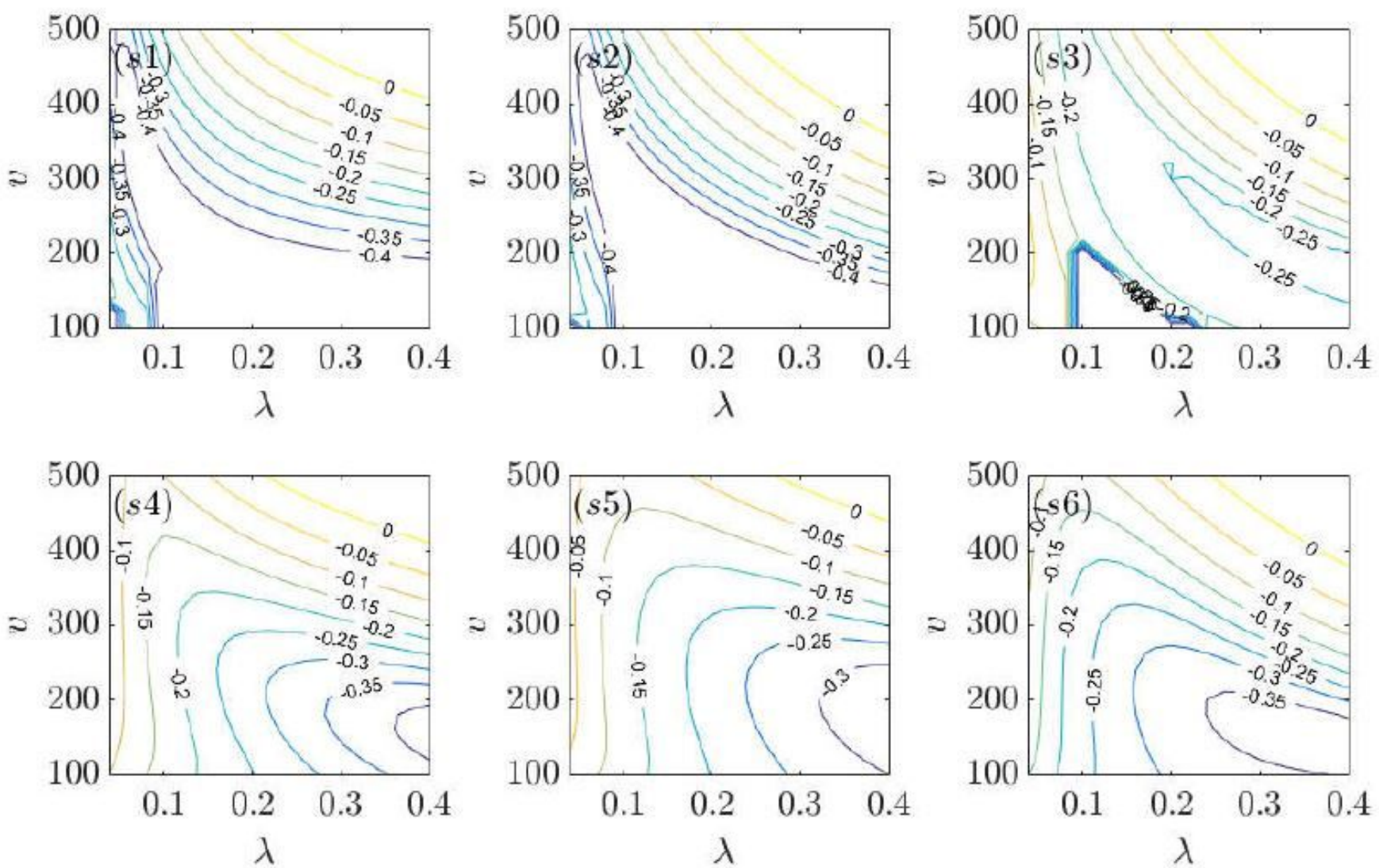

Figure 13

The contour of stability index with different speeds and equivalent conicities

\section{Supplementary Files}

This is a list of supplementary files associated with this preprint. Click to download.

- Appendix.docx 